\title{
A Delay between Motor Cortex Lesions and Neuronal Transplantation Enhances Graft Integration and Improves Repair and Recovery
}

\author{
Sophie Péron, ${ }^{1,2}$ @Marine Droguerre, ${ }^{1,2}$ Franck Debarbieux, ${ }^{3,4}$ - Nissrine Ballout, ${ }^{1,2}$ Marianne Benoit-Marand, ${ }^{1,2}$ \\ ๑Daureen Francheteau, ${ }^{1,2}$ @Sébastien Brot, ${ }^{1,2}$ Geneviève Rougon, ${ }^{3,4}$ Mohamed Jaber, ${ }^{1,2,5}$ and ${ }^{-A f s a n e h ~ G a i l l a r d ~}{ }^{1,2}$ \\ ${ }^{1}$ INSERM U1084, Experimental and Clinical Neurosciences Laboratory, Cellular Therapies in Brain Diseases Group, University of Poitiers, 86022 Poitiers \\ Cedex, France, ${ }^{2}$ Université de Poitiers, U1084, 86073 Poitiers Cedex, France, ${ }^{3}$ CNRS, UMR 7289, ImaPath, Institut de Neurosciences de la Timone, Faculté \\ de Médecine, 13005 Marseille, France, ${ }^{4}$ Aix-Marseille Université, 13284 Marseille Cedex 07, France, and ${ }^{5} \mathrm{CHU}$ de Poitiers, 86021 Poitiers Cedex, France
}

We previously reported that embryonic motor cortical neurons transplanted immediately after lesions in the adult mouse motor cortex restored damaged motor cortical pathways. A critical barrier hindering the application of transplantation strategies for a wide range of traumatic injuries is the determination of a suitable time window for therapeutic intervention. Here, we report that a 1 week delay between the lesion and transplantation significantly enhances graft vascularization, survival, and proliferation of grafted cells. More importantly, the delay dramatically increases the density of projections developed by grafted neurons and improves functional repair and recovery as assessed by intravital dynamic imaging and behavioral tests. These findings open new avenues in cell transplantation strategies as they indicate successful brain repair may occur following delayed transplantation.

Key words: cortical injury; delay; functional recovery; neuroanatomical repair; transplantation

\section{Significance Statement}

Cell transplantation represents a promising therapy for cortical trauma. We previously reported that embryonic motor cortical neurons transplanted immediately after lesions in the adult mouse motor cortex restored damaged cortical pathways. A critical barrier hindering the application of transplantation strategies for a wide range of traumatic injuries is the determination of a suitable time window for therapeutic intervention. We demonstrate that a 1 week delay between the lesion and transplantation significantly enhances graft vascularization, survival, proliferation, and the density of the projections developed by grafted neurons. More importantly, the delay has a beneficial impact on functional repair and recovery. These results impact the effectiveness of transplantation strategies in a wide range of traumatic injuries for which therapeutic intervention is not immediately feasible.

\section{Introduction}

Damage to the rodent adult motor cortex leads to deficits in motor function and loss of coordination (Whishaw et al., 2004; Ueno and Yamashita, 2011). One approach for overcoming the

Received Sept. 19, 2016; revised Dec. 21, 2016; accepted Jan. 4, 2017.

Author contributions: S.P., M.B.-M., and A.G. designed research; S.P., M.D., F.D., N.B., M.B.-M., M.F., S.B., and A.G. performed research; A.G. contributed unpublished reagents/analytic tools; S.P., M.D., F.D., N.B., M.B.-M., and A.G. analyzed data; S.P., F.D., M.B.-M., G.R., M.J., and A.G. wrote the paper.

This work was funded by grants from the Institut pour la Recherche sur la Moelle Epinière et l'Encéphale (IRME), Fonds Européen de Développement Régional (FEDER) №33552 and Contrat de Plan Etat-région (CPER 5) to A. G. and Agence Nationale de la Recherche (ANR) to F.D. We thank the staff of Image'UP platform (University of Poitiers).

The authors declare no competing financial interests.

Corresponding should be addressed to Afsaneh Gaillard, INSERM U1084, Experimental and Clinical Neurosciences

Laboratory, Cellular Therapies in Brain Diseases Group, University of Poitiers, 1 rue Georges Bonnet, BP 633, 86022 Poitiers Cedex, France. E-mail: afsaneh.gaillard@univ-poitiers.fr.

DOI:10.1523/JNEUROSCI.2936-16.2017

Copyright $\odot 2017$ the authors $\quad 0270-6474 / 17 / 371820-15 \$ 15.00 / 0$ generally limited capacity of the mature CNS to regenerate axons in response to cell loss is the transplantation of immature neurons (Gaillard et al., 1998). The efficacies of neuronal transplantation-based cell replacement therapies depend on the ability of the transplanted neurons to survive, differentiate, integrate in the remaining neuronal networks, and reconstruct the damaged pathways in the mature CNS. To be of clinical relevance, transplanted neurons should participate in the recovery of appropriate physiological responses to stimuli and amelioration of altered behavior.

We have previously reported that embryonic cortical neurons grafted into the adult mouse motor cortex in an acute cortical aspiration lesion model allowed reestablishment of the damaged pathways. The transplanted neurons developed projections toward all cortical and subcortical targets, including long-range projections reaching the spinal cord. In addition, the presence of 
reciprocal synaptic contacts between the host and the grafted neurons indicated a certain level of integration of the transplanted neurons in the host circuitry (Gaillard et al., 2007). While such robust axonal growth in the adult brain first aroused astonishment (Tuszynski, 2007), similar findings further confirmed the regenerative capacity of immature neuronal cells in other lesion models. These included severe spinal cord injury (Lu et al., 2012) and models of neurodegenerative disorders such as Parkinson's disease, where embryonic neurons transplanted within the substantia nigra develop projections reaching the striatal target region (Gaillard et al., 2009; Thompson et al., 2009). Moreover, visual cortical neurons derived in vitro from mouse embryonic stem cells exhibited a similar regenerative potential (Gaspard et al., 2008; 2009; Michelsen et al., 2015).

While these studies open the possibility of the use of cell transplantation for CNS repair, a serious limitation in the consideration of such approaches in a clinical setting is the delay in transplantation after injury, as neurons derived from embryonic or pluripotent stem cells may not be readily available. In addition, brain injury triggers reactive gliosis and a plethora of signals, including inflammatory response (Burda et al., 2016; Gadani et al., 2015), that may influence graft survival and development. As such, we previously observed that embryonic cortical neurons transplanted in the noninjured adult brain were not able to develop extensive axonal projections (Gaillard and Jaber, 2007) as opposed to the robust axonal growth developed by the same cortical progenitors when transplanted in the adult damaged cortex (Gaillard et al., 2007). In addition to the intrinsic capacity of cortical progenitors to develop toward a specific neuronal subtype according to its developmental program (Pinaudeau et al., 2000; Ballout et al., 2016; Gaillard et al., 2007), the environment in which the cells are transplanted thus appears to also strongly influence the graft outcome. Despite the hardly escapable occurrence of a delay between lesion and transplantation in a clinical context, during which the injury site is largely modified, its effects on various aspects of graft development remain largely ignored. Thus, a detailed anatomical and functional study of the consequences of a delay between lesion and transplantation is required.

In the present study, we aimed at rigorously characterizing the impact of a 1 week delay between the lesion and transplantation on the anatomical and functional integration of grafted cortical progenitors. For that, embryonic motor cortical tissue transplantation into the forelimb area of adult mice motor cortex was performed either immediately or 1 week after the cortical lesion. Transplanted animals were then killed at 4, 7, or $14 \mathrm{~d}$ following grafting for analysis of size, cell proliferation, survival, vascularization, and connectivity of the grafted tissue, in addition to a long-term (90 d) functional analysis of the impact of transplanted neurons on repair and recovery.

\section{Materials and Methods}

\section{Animals}

Housing of the animals and all animal experimental procedures were performed in accordance with the guidelines of the French Agriculture and Forestry Ministry (decree 87849) and the European Communities Council Directive (2010/63/EU). All efforts were made to reduce the number of animals used and their suffering. A total of 150 female mice were used in this study, as follows: 63 C57BL/6 mice were transplanted (and used for neuroanatomical, behavioral, and electrophysiological study), 22 EGFP mice were transplanted for study of the origin of the blood vessels in the transplants, 18 mice who failed to reach the criteria (at least 4 pellets collected) during behavioral test were eliminated, 12 mice were lesioned, 10 mice were used as control in behavioral study, 9 mice were used as control in electrophysiological study, and 17 mice were used for in vivo two-photon microscopy.

\section{Transplantation procedure}

Adult (3- to 6-month-old) C57BL/6 mice ( $n=63$; Janvier Labs) were used as recipients, and the transplantation procedure was performed as described previously (Gaillard and Roger, 2000). Unless otherwise specified, cortical donor tissue originated from embryonic day 14 transgenic mouse embryos overexpressing the enhanced green fluorescent protein (EGFP) under the control of a chicken $\beta$-actin promoter [C57BL/6$\operatorname{TgN}(\beta$-act-EGFP)] Osb strain (Okabe et al., 1997). Briefly, recipient animals were anesthetized with avertin $(250 \mathrm{mg} / \mathrm{kg}$ body weight, i.p.), and the motor cortex was aspirated from 0.5 to $2.5 \mathrm{~mm}$ rostral to the bregma and from 0.5 to $2.5 \mathrm{~mm}$ lateral to the midline, with the corpus callosum (cc) left intact. Motor cortical tissue was deposited into the host lesion cavity either immediately $(n=32)$ or $7 \mathrm{~d}(n=31)$ after the lesion. Care was taken to maintain the original dorsoventral and anteroposterior orientations of the cortical fragments during the transplantation procedure.

To allow better visualization of sprouting of the host vessels into the transplant, GFP transgenic mice were used as recipients $(n=22)$, and donor motor cortical tissue was obtained from C56BL/6 fetuses. Additionally, 17 mice were transplanted for in vivo two-photon microscopy vascularization dynamics analysis. After grafting, a round glass coverslip (diameter, $6 \mathrm{~mm}$ ) was glued with a histocompatible acrylic glue (Cyanolit, Panacol) on the surrounding bone. Bone surface was previously thinned to maximize glass contact with brain and grafted tissue while taking care to impose virtually no pressure. Bone was scratched and dried to improve later adherence of the glue. A drop of PBS was applied only in the center of the window before placing the glass coverslip, and then the glue was generously applied. Spreading was observed around and below the glass, but it was limited forward at the interface with the PBS drop due to the hydrophobicity of the glue. Once dried, the tight seal of the glue was further reinforced with dental cement.

\section{In vivo two-photon microscopy and data analysis}

Prior to each imaging session, mice were anesthetized with an intraperitoneal injection of a mixture of xylazine/ketamine $(10$ and $100 \mathrm{mg} / \mathrm{kg}$, respectively) and injected intravenously with $100 \mu \mathrm{l}$ of a RhodamineB or a Cascade Blue-conjugated $70 \mathrm{kDa}$ dextran solution $(20 \mathrm{mg} / \mathrm{ml}$ in PBS; Sigma-Aldrich). Care was taken to alternate each conjugate to limit the contaminating accumulation of fluorescence in macrophages (Fenrich et al., 2012). Animals were positioned on a homemade stereotactic frame whose angular position could be adjusted in all directions to ensure perfect planar repositioning of the animal under a $20 \times$ water-immersion objective (numerical aperture, 1.0). Anesthesia was supplemented hourly to prevent toe pinch reflex.

We used home-modified Zeiss two-photon microscopes (LSM7MP) to fit mice below the objective and coupled them to a femtosecond pulsed infrared laser (Mai-Tai, Spectra-Physics) tuned at 800 or $840 \mathrm{~nm}$. GFP (520-555 nm), RhodamineB (605-650 nm), and Cascade Blue (400$480 \mathrm{~nm}$ ) signals were simultaneously collected on three non-descanned detectors. Detector gains were set to use all the 12 bit dynamic range on each channel, while laser intensity was adjusted according to depth. Optimal intensity parameters were defined every $50 \mu \mathrm{m}$ for each mouse before starting tiled acquisition. These parameters were linearly interpolated for intermediate depth values. Twenty-five fields of view were typically acquired to completely cover the glass window (approximately a $2 \times 2 \times 2 \mathrm{~mm}$ area) over a depth of $500 \mu \mathrm{m}$ using $5 \mu \mathrm{m}$ steps. Mice underwent imaging sessions at 4 and $7 \mathrm{~d}$ postimplantation and, if clarity of the window permitted, also at $14 \mathrm{~d}$. Data from each channel were median filtered and analyzed separately using ImageJ software. Vascular $3 \mathrm{D}$ image stacks were segmented semiautomatically using the Otsu method, while the area occupied by the graft was identified based on a Huang thresholding paradigm. The blood supply inside the graft was expressed as the vascular voxel density inside the thresholded graft volume. Data were expressed as the mean \pm SEM over the mice. Illustrations in the figures correspond to $3 \mathrm{D}$ projections of the image stacks using a depth cueing algorithm available in ImageJ. 


\section{Neuroanatomical studies}

Fifty-five mice were used for postmortem studies to determine projections developed by the transplant, angiogenesis, cellular proliferation, and cellular survival in the transplant on free-floating sections.

$B r d U$ injections. To assess cellular proliferation in the graft, mice received two daily injections of $\mathrm{BrdU}$ ( $50 \mathrm{mg} / \mathrm{kg}, 0.1 \mathrm{M} \mathrm{NaOH}, \mathrm{NaCl} 0.9 \%$, i.p.; Sigma-Aldrich) separated by $4 \mathrm{~h}$ during the $3 \mathrm{~d}$ following transplantation. They were killed at 4,7 , and $14 \mathrm{~d}$ post-transplantation (dpt) to evaluate BrdU incorporation.

Tissue processing. Mice were injected with a lethal dose of avertin and perfused transcardially with $150 \mathrm{ml}$ of saline $(0.9 \%)$, followed by $200 \mathrm{ml}$ of ice-cold paraformaldehyde (PFA; $4 \%$ ) in $0.1 \mathrm{~m}$ phosphate buffer (PB, $\mathrm{pH}$ 7.4). Brains and spinal cords were removed and postfixed in $4 \% \mathrm{PFA}$ overnight. Brains were cut into $40 \mu \mathrm{m}$ coronal section with a vibrating microtome (Microm HM650V, Thermo Scientific) and stored in a cryoprotective solution ( $20 \%$ glucose, $40 \%$ ethylene glycol, $0.025 \%$ sodium azide, and $0.05 \mathrm{M}$ phosphate buffer, $\mathrm{pH}$ 7.4). Spinal cords were cryoprotected in a $30 \%$ sucrose solution overnight, cut on a freezing microtome (Microm HM450, Thermo Scientific) in $40 \mu \mathrm{m}$ coronal sections and stored in cryoprotective solution.

Immunohistochemistry. Free-floating sections were incubated for $1 \mathrm{~h}$ at room temperature (RT) in a blocking solution (5\% donkey serum, $0.3 \%$ Triton X-100 in TBS $0.1 \mathrm{~m}, \mathrm{pH}$ 7.6). Primary antibodies, diluted in blocking solution, were applied for $2 \mathrm{~h}$ at RT and overnight at $4^{\circ} \mathrm{C}$. Appropriate secondary antibodies were diluted in blocking solution and applied for $1 \mathrm{~h}$ at RT. The following antibodies were used: rabbit anti-GFP (1:1000; catalog \#A6455, Molecular Probes, ThermoFisher Scientific), goat antidoublecortin (DCX; 1:300; sc-8066, Santa Cruz Biotechnologies), rat anti-CD31 (1:250; catalog \#553370, BD Biosciences), and rat anti-BrdU (1:200; OBT0030, Serotec). For BrdU staining, sections were pretreated with $2 \mathrm{~N} \mathrm{HCl}$ and $0.5 \%$ Triton $\mathrm{X}-100$ for $30 \mathrm{~min}$ at $37^{\circ} \mathrm{C}$ followed by incubation with Borax, $\mathrm{pH}$ 8.6, for 30 min at RT and blocking with 3\% bovine serum albumin (Sigma-Aldrich), $0.3 \%$ Triton X-100 in PBS $0.1 \mathrm{M}$, $\mathrm{pH}$ 7.4. The sections were covered with DEPEX Mounting Media (VWR).

Terminal deoxynucleotidyl transferase-mediated biotinylated UTP nick end labeling procedure. To examine apoptotic cell death of grafted tissue, terminal deoxynucleotidyl transferase-mediated biotinylated UTP nick end labeling (TUNEL) was performed on free-floating sections using a protocol modified from the study by Bessert and Skoff (1999). Sections were rinsed three times for $10 \mathrm{~min}$ at RT in $0.1 \mathrm{M} \mathrm{PBS}, \mathrm{pH}$ 7.4, treated for 15 min at RT with $0.3 \%$ Triton X-100 in $0.1 \mathrm{M} \mathrm{PBS,} \mathrm{pH} \mathrm{7.4,} \mathrm{and} \mathrm{rinsed}$ three times for $10 \mathrm{~min}$ in $0.1 \mathrm{M} \mathrm{PBS}, \mathrm{pH}$ 7.4. Sections were treated with $200 \mathrm{ng} / \mathrm{ml}$ proteinase $\mathrm{K}$ (Invitrogen) in $0.1 \mathrm{M}$ Tris $\mathrm{HCl}, \mathrm{pH}$ 8.0, $0.05 \mathrm{M}$ EDTA for $6 \mathrm{~min}$ at $37^{\circ} \mathrm{C}$, and washed in $0.1 \mathrm{~m}$ glycine in $0.1 \mathrm{M} \mathrm{PBS}$, pH 7.4 for $5 \mathrm{~min}$ at RT. Sections were incubated in $0.25 \%$ anhydrous acetic acid in $0.1 \mathrm{M}$ triethanolamine, $\mathrm{pH} 8.0$, and $0.9 \% \mathrm{NaCl}$ for $10 \mathrm{~min}$ at $\mathrm{RT}$, and rinsed for $10 \mathrm{~min}$ at $\mathrm{RT}$ in sterile distilled $\mathrm{H}_{2} \mathrm{O}$ and for $5 \mathrm{~min}$ in $0.1 \mathrm{~m}$ PBS, pH 7.4, at RT. Then, the sections were treated for $20 \mathrm{~min}$

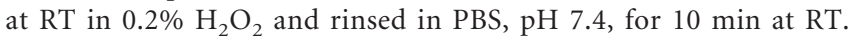
Sections were incubated in TUNEL reaction mixture from the In Situ Cell Death Detection Kit TMR Red (Roche) diluted two times in TUNEL dilution buffer ( $30 \mathrm{~mm}$ Tris/ $\mathrm{HCl}, 140 \mathrm{~mm}$ sodium cacodylate and $1 \mathrm{mM} \mathrm{CoCl}_{2}$ ) for $1 \mathrm{~h}$ at $37^{\circ} \mathrm{C}$ and washed three times for $10 \mathrm{~min}$ at $\mathrm{RT}$ in $0.1 \mathrm{M}$ PBS, pH 7.4.

\section{Data acquisition and quantification}

For each animal, the surface occupied with blood vessels and the number of BrdU and TUNEL ${ }^{+}$cells within the entire graft surface were quantified in five equally spaced sections ( 240 or $480 \mu \mathrm{m}$, depending on the size of the transplant) in five animals per group. For blood vessel quantification, images were taken with an MVX 10 Microscope (Olympus), and the density of CD31 labeling was determined using Mercator Pro software (Explora Nova). Results were expressed as the density of blood vessels in the graft (calculated: total surface of blood vessels/total surface of the transplant). BrdU ${ }^{+}$cell quantification was performed with Mercator Pro software (Explora Nova) on pictures taken with a Leica DM5500B Microscope. TUNEL ${ }^{+}$cells were counted manually on a Zeiss Axio Imager.M2 Apotome microscope at $40 \times$ magnification. $\mathrm{GFP}^{+}$cells were quantified for each animal on five sections for each area, using a highmagnification objective $(20 \times)$. For each group, fiber-labeling indexes were obtained by calculating the mean \pm SD total number of labeled fibers.

The transplant surfaces were calculated with Mercator Pro software (Explora Nova), and the transplant volume was calculated with the following formula: $V\left(\mathrm{~mm}^{3}\right)=\left[\left(s_{1}+s_{2}\right) / 2\right] \times d$ [where $s=$ surfaces (in square millimeters) and $d=$ distance (in millimeters) between two sections].

\section{Intracortical microstimulation}

Three months after grafting, the functional outcome of the graft was assessed by electrically stimulating the graft to evoke a motor response. Animals were anesthetized with ketamine $(150 \mathrm{mg} / \mathrm{kg}$, i.p.) and xylazine $(10 \mathrm{mg} / \mathrm{kg}$, i.p. $)$, and were placed in a stereotaxic frame and maintained at $37^{\circ} \mathrm{C}$ throughout the experiment. Stimulating concentric bipolar electrodes (SNEX-100, Kopf) were lowered at different coordinates to map the motor cortex. Stimulation currents were applied by an external stimulator (model DS3, Digitimer) triggered by a 1401 Plus System (Cambridge Electronic Design). Diffusion current around the stimulating electrode was assessed by recording the current evoked by stimulation at different distances from the stimulating electrode. The recording pipette was filled with $0.4 \mathrm{M} \mathrm{NaCl}$ and lowered at $50 \mu \mathrm{m}$ from the tip of the stimulating electrode. Diffusing currents were recorded with a Multiclamp (Molecular Devices), amplified 100 times, and filtered for spike recordings (low-pass filter at $300 \mathrm{~Hz}$ and high-pass filter at $10 \mathrm{kHz}$ ). The output signal was digitized by a CED Micro1401 (Cambridge Electronic Design) and acquired using Spike 2 software (Cambridge Electronic Design) for off-line analysis. In transplanted mice, the site of transplantation was visually identified to optimize electrode placement. Moreover, for every grafted mouse the cortex contralateral to the graft was tested to control for the stimulating electrode threshold in host tissue before starting the investigation of grafted tissue. Motor responses to stimulations were monitored throughout the experiment. Stimulation trains $(350 \mathrm{~Hz}$, $40 \mathrm{~ms}$ ) were applied at $1 \mathrm{~Hz}$, the evoked motor response was visually controlled and monitored by a camera.

\section{Behavioral analysis}

We examined whether cortical transplants can ameliorate motor deficits induced by lesion of the adult motor cortex. Functional assessment was performed using the staircase test, which allows side-specific measurement in paw-reaching ability (Montoya et al., 1991; Baird et al., 2001). The experimental procedure was designed based on the protocol described by Baird et al. (2001). Seventy mice were first habituated with sucrose reward pellets ( $20 \mathrm{mg}$; BioServe) by placing $\sim 50$ pellets in each cage during 3 consecutive days. Second, mice were familiarized with the staircase apparatus (Campden Instruments) during 5 consecutive days: during 15 min sessions, mice were placed on the apparatus, and sucrose reward pellets were placed along the central wall and on each step (two pellets/step) of the staircase. For a further training period of 2 months duration, the staircase was filled with one sucrose pellet per step, and mice were placed in the start chamber for $15 \mathrm{~min}$. Baseline scores were recorded, and mice that did not properly learn the test (i.e., collected less than three pellets/side) were excluded from the study. The others $(n=$ 52 ) were randomly divided into the following four experimental groups: control $(n=10)$, lesioned $(n=12)$, lesioned and transplanted without delay $(n=15)$, and lesioned and transplanted with a 1 week delay $(n=$ 15). Mice were tested 5 consecutive days/week with the staircase test for 3 postoperative months. Due to a slight decrease in performance on the first weekly testing day, only the four next-day scores were considered for analysis. For data acquisition, the session duration was set at $15 \mathrm{~min}$, and one reward pellet was placed on each step of the staircase. Mice were food deprived for $20 \mathrm{~h}$ before testing. The contralateral forepaw performance was calculated as the mean number (normalized with presurgical values; Bouët et al., 2007; Harris et al., 2010; Roome et al., 2014) of pellets consumed with the forepaw affected by the lesion (i.e., contralateral to the lesion). Histological analysis of the brains was performed after the behavioral testing period, and three animals from the no-delay group and two animals from the delay group were excluded from the study due to the lack of survival of the transplant. 

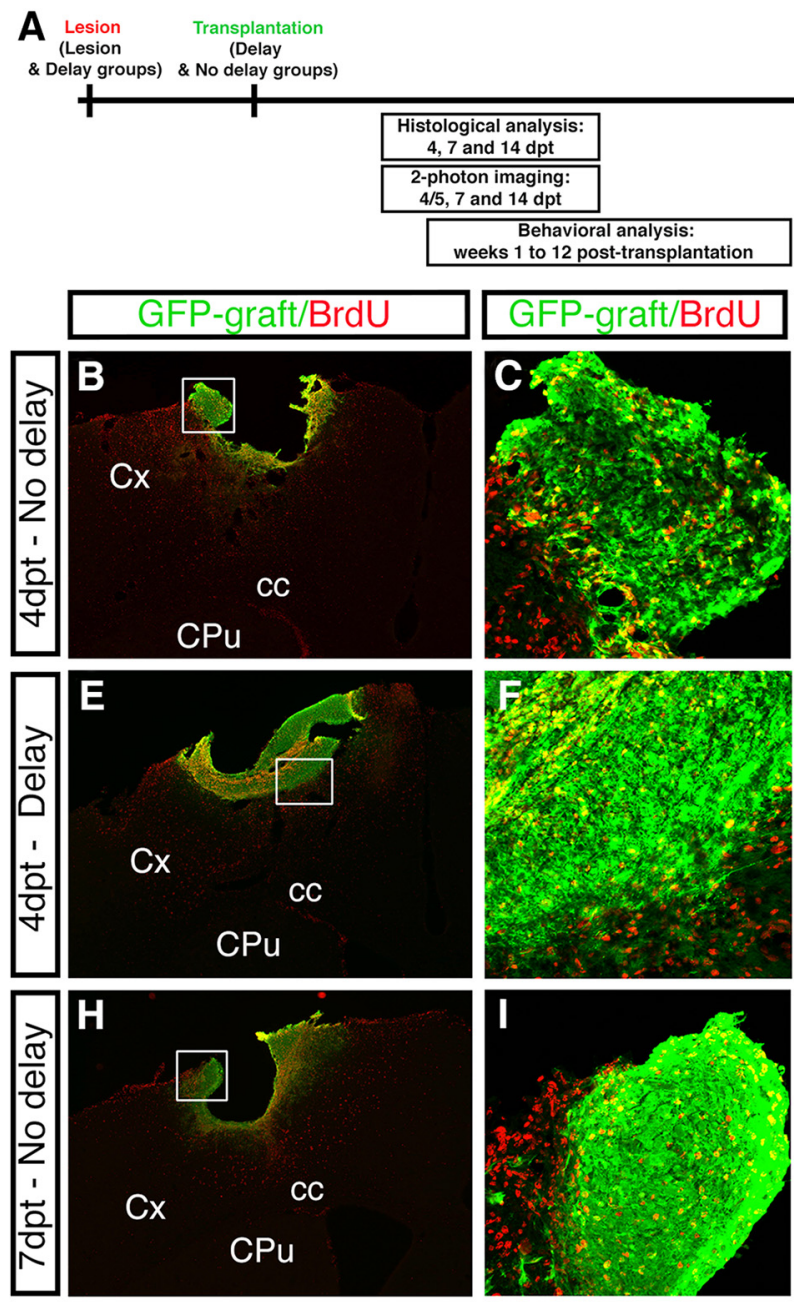

Electrophysiology \& histology:
3 months post-transplantation
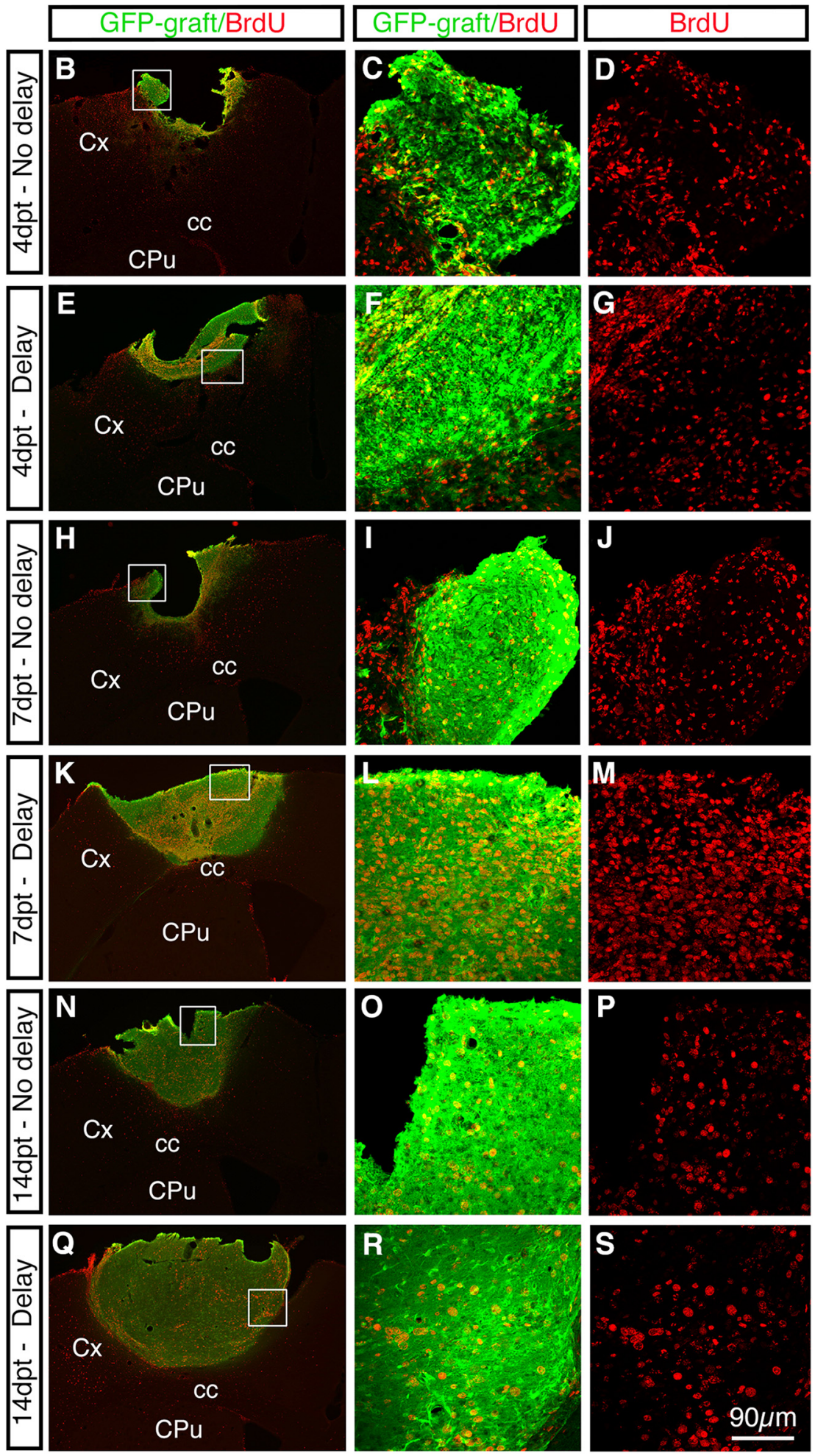

Figure 1. A, Time line of the study. $\boldsymbol{B}, \boldsymbol{E}, \boldsymbol{H}, \boldsymbol{K}, \boldsymbol{N}, \boldsymbol{Q}, \mathrm{Graft}$ development and cellular proliferation. Low-magnification images of coronal sections showing BrdU ${ }^{+}$cells (in red) in the GFP ${ }^{+}$transplants (in green) at $4 \mathrm{~d}(\boldsymbol{B}, \boldsymbol{E}), 7 \mathrm{~d}(\boldsymbol{H}, \boldsymbol{K})$, and $14 \mathrm{~d}(\boldsymbol{N}, \boldsymbol{Q})$ after

Statistical analysis

All the results concerning postmortem and behavioral studies are expressed as the mean \pm SD. For data concerning the transplant size, cellular proliferation, apoptosis, and vascularization levels in the transplants, statistical significance was evaluated using a two-way ANOVA having as factors time (4, 7, and $14 \mathrm{~d}$ ) and group (no-delay, delay), followed by Fisher's PLSD post hoc test. For data concerning fiber quantification, comparison between groups was performed using twoway ANOVA $\left(F_{(1,24)}=74.72, p<0.0001\right.$; $\left.F_{(1,45)}=72.48, p<0.0001\right)$ followed by post hoc comparison using Sidak's multiple-comparisons tests (delay vs no delay for each structure). Comparisons of the survival rates of the transplants were performed using logistic regression test. In vivo two-photon microscopy data were tested for significance using a MannWhitney two-tailed $U$ test. Statistical significance in the electrophysiological study was evaluated using the Kruskal-Wallis test for comparison of stimulation thresholds among all groups and a two-way ANOVA followed by a Bonferroni's post hoc test for comparison of stimulation thresholds versus depth. Performance in the staircase test within each experimental group at the different postoperative weeks was evaluated using one-way ANOVA with time as factor, followed by Fisher's PLSD post hoc test. The staircase test performance significance between groups was evaluated by two-way repeated-measures ANOVA having time and group (control, lesioned, lesioned and transplanted without delay, and lesioned and transplanted with delay) as factors, followed by Fisher's PLSD post hoc test. The level of statistical significance was set at $p<0.05$.

\section{Results}

Development of the transplants

To determine the most appropriate time window for cortical transplantation, we evaluated in a pilot study the consequences of a delay between cortical injury and transplantation on the development of transplanted embryonic cells. We took advantage of the well described model of transplantation of embryonic-derived cortical neurons and transplanted (embryonic day 14) motor cortical neurons into the motor cortex of adult mice 5,7 , or

transplantation without delay $(\boldsymbol{B}, \boldsymbol{H}, \boldsymbol{N})$ or with delay $(\boldsymbol{E}, \boldsymbol{K}$, and Q) after cortical lesion. $\boldsymbol{C}, \boldsymbol{D}, \boldsymbol{F}, \boldsymbol{G}, \boldsymbol{I}, \boldsymbol{J}, \boldsymbol{L}, \boldsymbol{M}, \mathbf{O}, \boldsymbol{P}, \boldsymbol{R}$, and $\boldsymbol{S}$, High-magnification images within the graft showing BrdU cells (red) in the GFP ${ }^{+}$transplants (green) at $4 \mathrm{~d}(\boldsymbol{C}, \boldsymbol{D}, \boldsymbol{F}$, and $\boldsymbol{G}), 7 \mathrm{~d}(\boldsymbol{I}, \boldsymbol{J}, \boldsymbol{L}$, and $\boldsymbol{M})$, and $14 \mathrm{~d}(\boldsymbol{O}, \boldsymbol{P}, \boldsymbol{R}$, and $\boldsymbol{S})$ after transplantation without delay $(\boldsymbol{C}, \boldsymbol{D}, \boldsymbol{I}, \boldsymbol{J}, \mathbf{0}$, and $\boldsymbol{P})$ or with delay $(\boldsymbol{F}, \boldsymbol{G}, \boldsymbol{L}$, $M, R$, and $S$ ) following cortical lesion. The increased number of proliferating cells is accompanied by an increased size of the grafts when transplantation is performed with delay $(\boldsymbol{E}-\boldsymbol{G}$, $\boldsymbol{K}-\boldsymbol{M}$, and $\mathbf{Q}-\boldsymbol{S})$ compared with no delay ( $\boldsymbol{B}-\boldsymbol{D}, \boldsymbol{H}-\boldsymbol{J}$, and $\boldsymbol{N}-\boldsymbol{P})$. (X, Cortex. Scale bars: $\boldsymbol{B}, \boldsymbol{E}, \boldsymbol{H}, \boldsymbol{K}, \boldsymbol{N}, \boldsymbol{Q}, 600 \mu \mathrm{m} ; \boldsymbol{C}, \boldsymbol{D}, \boldsymbol{F}$, $G, I, J, L, M, O, P, R$, and $S, 90 \mu \mathrm{m}$. 
A

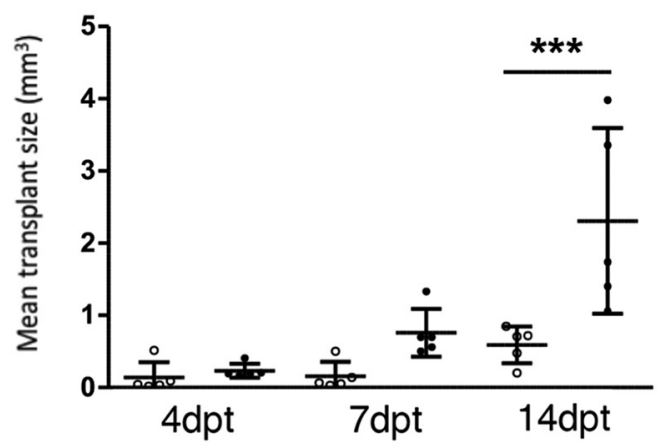

C

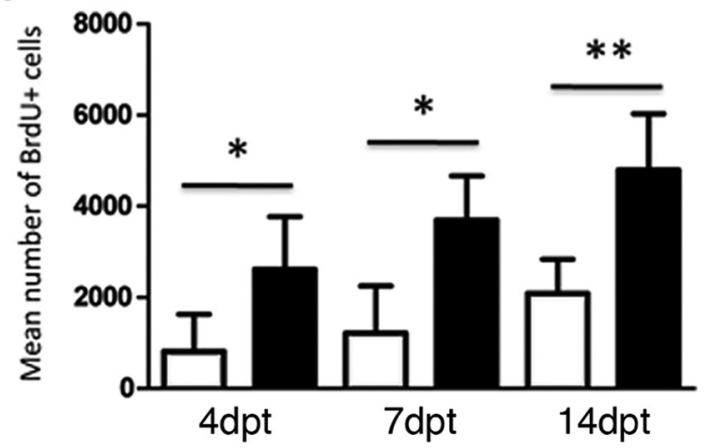

B

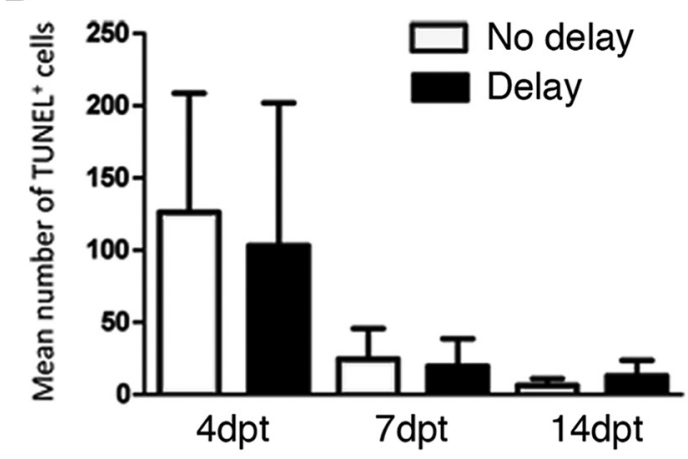

D

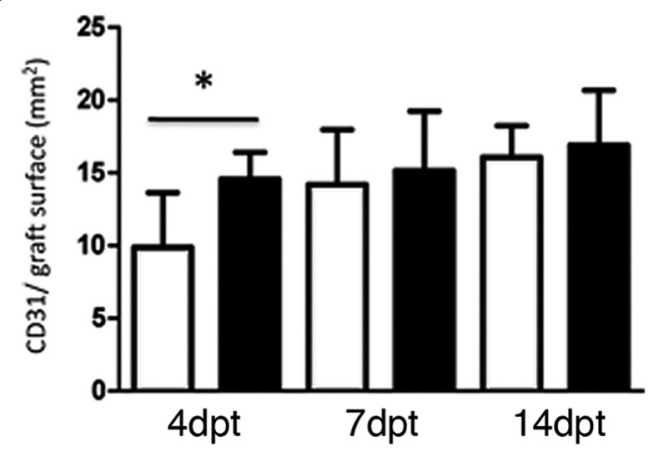

Figure 2. Quantitative analysis of the development and the vascularization of the transplant. $\boldsymbol{A}$, Measurement of the size of the transplants (in cubic millimeters) at different time points (4, 7, and $14 \mathrm{~d}$ ) after transplantation with or without delay after the cortical lesion. A significant increase in the volume of the transplants is observed when transplantation is performed 1 week after the cortical lesion and the killing of the mice $14 \mathrm{~d}$ after. B, Quantification of TUNEL ${ }^{+}$cell number in the transplants 4, 7, and $14 \mathrm{~d}$ after transplantation without or with delay after the cortical lesion. The postlesion time of transplantation does not influence the number of transplanted cells undergoing the apoptotic process. C, Quantification of BrdU ${ }^{+}$cell number in the transplants 4,7 , and $14 \mathrm{~d}$ after transplantation without or with delay following lesion. A significant increase of BrdU ${ }^{+}$cells is found in the transplants at the three time points when transplantation is performed with a delay after the cortical lesion. $\boldsymbol{D}$, Measurement of the vascularization of the transplants expressed as the CD31 ${ }^{+}$blood vessels surface/GFP ${ }^{+}$graft surface ratio at 4 , 7 , and $14 \mathrm{~d}$ after transplantation with or without delay following cortical lesion. A significant increase in transplant vascularization is observed $4 \mathrm{~d}$ after transplantation with delay after the cortical lesion compared with no delay. Data are presented as the group mean \pm SD, and asterisks indicate significant intergroup differences: two-way ANOVA followed by Fisher's PLSD, ${ }^{* * *} p<0.0001$; ${ }^{* *} p<0.001 ;{ }^{*} p<0.05$.

$30 \mathrm{~d}$ after a cortical lesion. Our results indicated that a delay of 1 week between the lesion and transplantation was superior to other delay periods tested ( 5 and $30 \mathrm{~d}$ ), with respect to the levels of cellular proliferation in the grafts and the density of projections developed by the transplanted neurons (data not shown). We thus decided to focus this study on the deep analysis of the effects of a $7 \mathrm{~d}$ delay between lesion and transplantation.

To evaluate the effect of a delay between lesion and grafting on the growth of the transplanted tissue, the volume of the graft was measured at three different time points after transplantation (Fig. 1). At $4 \mathrm{dpt}$, there was no significant difference in the graft volume between the two groups of transplanted animals (no-delay group, $0.14 \pm 0.21 \mathrm{~mm}^{3}$; delay group, $0.23 \pm 0.10 \mathrm{~mm}^{3} ; n=5$; Fig. $1 B, E$ ). At $7 \mathrm{dpt}$, tissue transplanted with a delay (Fig. $1 K$ ) almost filled the lesion cavity, and its volume tended to be increased compared with that in animals transplanted without delay (Fig. $1 H$; no-delay group, $0.16 \pm 0.20 \mathrm{~mm}^{3}$; delay group, $\left.0.76 \pm 0.33 \mathrm{~mm}^{3}\right)$, although the difference was not significant $(p=0.1061, n=5)$. At $14 \mathrm{dpt}$, a significant (fourfold) increase of the volume of tissue transplanted with a 1 week delay (Fig. $1 Q)$ was observed compared with tissue transplanted without delay (Figs. $1 \mathrm{~N}, 2 \mathrm{~A}$; no-delay group, $0.59 \pm 0.25 \mathrm{~mm}^{3}$; delay group, $\left.2.31 \pm 1.29 \mathrm{~mm}^{3} ; p<0.0001, n=5\right)$. Graft size depends on the balance between cell death and cell proliferation, and as such the observed increase in graft size may have been due either to a decrease in cell death or/and an increase in cell proliferation.
Cell apoptosis in the grafts was detected by a TUNEL assay at 4, 7, and $14 \mathrm{dpt}$. Numerous apoptotic cells were present in the transplants at $4 \mathrm{dpt}$ in the two transplanted groups (no-delay group, $126 \pm 82$; delay group, $103 \pm 99 ; n=5$; Fig. $2 B$ ). At $7 \mathrm{dpt}$, the density of apoptotic cells observed in the transplants decreased significantly compared with $4 \mathrm{dpt}$ in both groups (nodelay group, $24 \pm 21$; delay group, $20 \pm 19, n=5$ /group). Apoptotic cells became scarce at $14 \mathrm{dpt}$ (no-delay group, $6 \pm 4$; delay group, $13 \pm 11 ; n=5$ ). No significant difference in the number of $\mathrm{TUNEL}^{+}$cells was found between the two transplanted groups at any time examined (Fig. 2B). Consistently, the survival rate of the transplants, calculated as the percentage of transplanted mice exhibiting a transplant at the time of analysis, was not statistically different between the two transplanted groups (no-delay group, 79\%; delay group, 96\%).

To analyze the proliferation of grafted cells, BrdU incorporation was measured. Quantification of $\mathrm{BrdU}^{+}$cells in the transplants showed that a delay between lesion and transplantation significantly increased the proliferation of the grafted cells at all time points ( $4 \mathrm{dpt}$ : no-delay group, $815 \pm 816$; delay group, $2616 \pm 1151 ; p<0.001 ; 7 \mathrm{dpt}$ : no-delay group, $1220 \pm 1028$; delay group, $3694 \pm 967 ; p<0.001$; $14 \mathrm{dpt}$ : no-delay group, $2087 \pm 749$; delay group, $4794 \pm 1235 ; p<0.001, n=5$; Figs. $1 B-S, 2 C)$. Together, our results show that increased graft size in the delay group resulted mainly from increased cellular proliferation rather than decreased cellular apoptosis. 

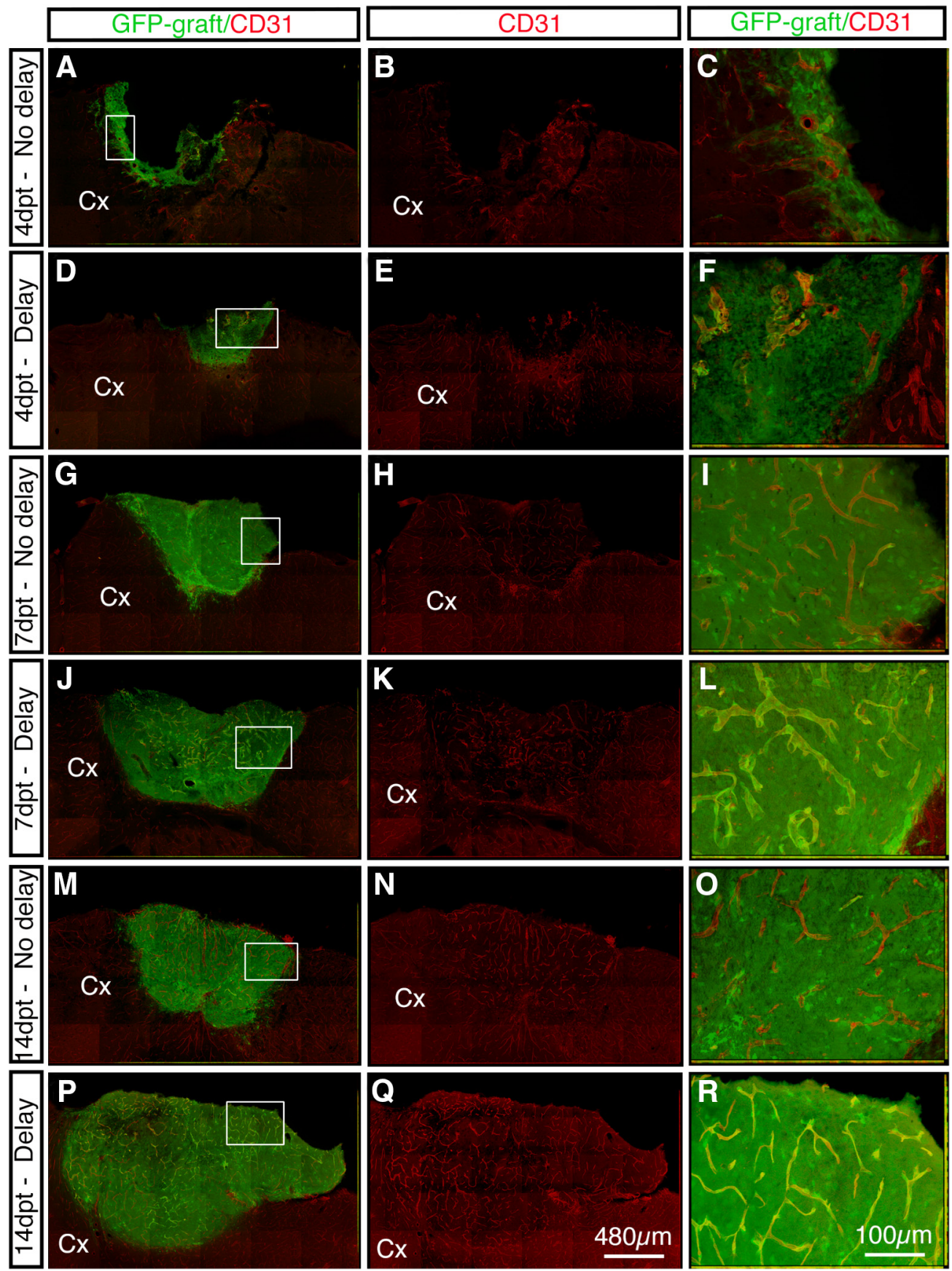

Figure 3. Vascularization of the transplant. $A, B, D, E, G, H, J, K, M, N, P$, and $Q$, Low-magnification photomicrographs of coronal sections illustrating immunolabeled $C D 31^{+}$blood vessels (red) in $G F P{ }^{+}$ transplants (green) at $4 \mathrm{~d}(\boldsymbol{A}, \boldsymbol{B}, \boldsymbol{D}$, and $\boldsymbol{E}), 7 \mathrm{~d}(\boldsymbol{G}, \boldsymbol{H}, \boldsymbol{J}$, and $\boldsymbol{K})$, and $14 \mathrm{~d}(\boldsymbol{M}, \boldsymbol{N}, \boldsymbol{P}$, and $\boldsymbol{Q})$ after transplantation without delay $(\boldsymbol{A}, \boldsymbol{B}, \boldsymbol{G}, \boldsymbol{H}, \boldsymbol{M}$, and $\boldsymbol{M})$ or with delay $(\boldsymbol{D}, \boldsymbol{E}, \boldsymbol{J}, \boldsymbol{K}, \boldsymbol{P}$, and $\boldsymbol{Q})$ after the cortical lesion. $\boldsymbol{C}, \boldsymbol{F}$, $\boldsymbol{I}, L, \mathbf{O}, \boldsymbol{R}$, High-magnification images from regions of interest located inside the graft showing immunolabeled $\left(\mathrm{D} 31^{+}\right.$blood vessels (red) in $\mathrm{GFP}^{+}$transplants $(\mathrm{green})$ at $4 \mathrm{~d}(\boldsymbol{C}, \boldsymbol{F}), 7 \mathrm{~d}(\boldsymbol{I}, \boldsymbol{L})$ and $14 \mathrm{~d}(\mathbf{O}, \boldsymbol{R})$ after transplantation without delay $(\boldsymbol{C}, \boldsymbol{I}, \mathbf{O})$ or with delay $(\boldsymbol{F}, \boldsymbol{L}, \boldsymbol{R})$ after the cortical lesion. $(\mathrm{C}$, Cortex. Scale bars: $A, B, D, E, G, H, J, K, M, N, P, Q, 480 \mu \mathrm{m} ; C, F, I, L, O, R, 100 \mu \mathrm{m}$.

\section{Vascularization of the graft}

We hypothesized that the observed increased cellular proliferation and graft size in the delay group might be associated with increased vascularization of the grafts, providing a better supply of oxygen and metabolic compounds. Quantification of CD31immunostained blood vessels in the $\mathrm{GFP}^{+}$grafts showed that a delay between lesion and transplantation led to a transient but significant increase in the vascularization of grafts at $4 \mathrm{dpt}$ (nodelay group, $9.9 \pm 3.7$; delay group, $14.6 \pm 1.8 ; p<0.05 ; n=5$; Figs. $2 D, 3 A-F)$. No quantitative differences in graft vascularization density were observed at $7 \mathrm{dpt}$ (Figs. $2 D, 3 G-L$ ) or $14 \mathrm{dpt}$
(Figs. 2D, 3M-R) between the no-delay group and the delay group (7 dpt: no-delay group, $14.2 \pm 3.8$; delay group, $15.2 \pm 4.1$; $n=5 ; 14$ dpt: no-delay group, $16.1 \pm 2.2$; delay group, $16.9 \pm 3.8$; $n=5$ ). Intriguingly, double labeling for GFP and CD31 revealed a difference in the origin of the endothelial cells found in the transplant vasculature in relation to the time of transplantation following the lesion. Indeed, very few $\mathrm{CD} 31^{+} / \mathrm{GFP}^{+}$blood vessels were found in the cortical tissue transplanted without a delay after cortical lesion, indicating that the blood supply in this group originated primarily from regenerated host vessels. By contrast, numerous $\mathrm{CD} 31^{+} / \mathrm{GFP}^{+}$blood vessels were found in the delay 

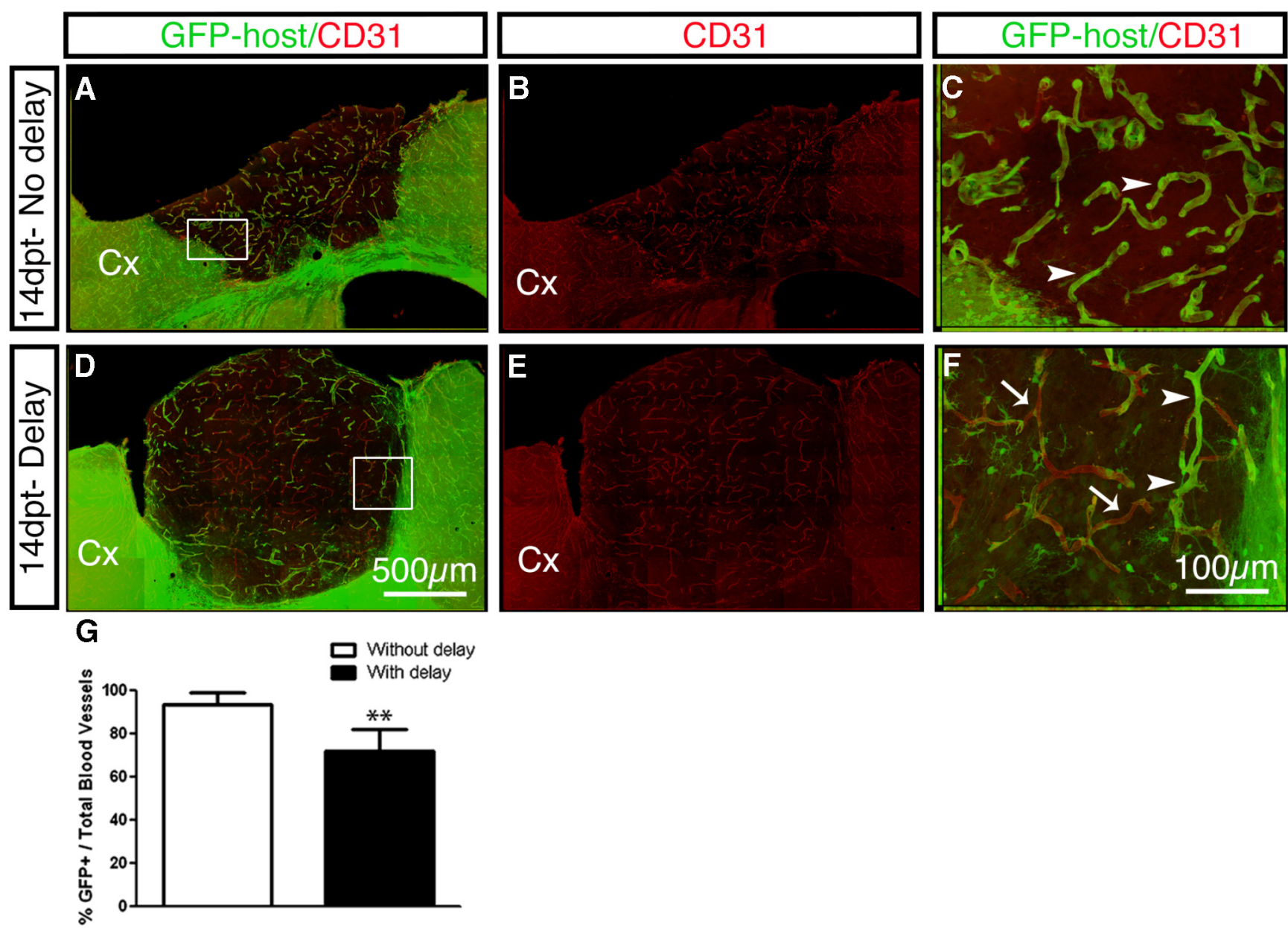

Figure 4. Origin of blood vessels in the transplant. $A, B, D, E$, Low-magnification micrographs of coronal sections showing immunolabeled CD31 ${ }^{+}$blood vessels (red) in the transplants $14 \mathrm{~d}$ after transplantation in the motor cortex of $\mathrm{GFP}^{+}$mice (green) without $(\boldsymbol{A}, \boldsymbol{B})$ or with $(\boldsymbol{D}, \boldsymbol{E})$ delay after the cortical lesion. $\boldsymbol{C}, \boldsymbol{F}$, High-magnification images from regions of interest located inside the graft showing immunolabeled $\mathrm{CD}_{1}{ }^{+}$blood vessels (red) in the transplants $14 \mathrm{~d}$ after transplantation in the motor cortex of $\mathrm{GFP}^{+}$mice (green) without a delay $(\boldsymbol{C})$ or with a delay $(\boldsymbol{F})$ after the cortical lesion. The data indicate that when transplantation is performed immediately after the cortical lesion, vascularization of the transplants depends mainly on the regenerated host blood vessels (arrows). On the contrary, when transplantation is performed 1 week after the cortical lesion, the blood vessels in the transplants originate from both host (arrows) and donor (arrowheads). Quantification at $14 \mathrm{~d}$ after transplantation confirms that cortical tissue transplanted without delay almost exclusively depends on the host blood supply. The percentage of GFP ${ }^{+}$blood vessels originating from the host is significantly reduced in cortical tissue transplanted with a delay, which is indicative of the development of blood vessels originating from the graft in the context of delayed transplantation (mean $\pm S D, t$ test, ${ }^{* *} p<0.001 ; \boldsymbol{G}$ ). CX, Cortex. Scale bars: $\boldsymbol{A}, \boldsymbol{B}, \boldsymbol{D}, \boldsymbol{E}, 500 \mu \mathrm{m} ; \boldsymbol{C}, \boldsymbol{F}, 100 \mu \mathrm{m}$.

group, indicating that the vascular supply of the graft is derived from both host and donor vessels. This observation was further confirmed by transplanting motor cortical tissue obtained from wild-type animals into the motor cortex of GFP ${ }^{+}$animals. Thus, we clearly observed that, in the delay group, vascularization was indeed derived from both host and transplant (Fig. 4A-F). Accordingly, the ratio of blood vessels originating from the host/ total blood vessels in the transplants was significantly reduced in the delay group (no-delay group, $93.3 \pm 5.7 \%$; delay group, $71.8 \pm 10.2 \% ; p<0.001 ; n=5$; Fig. $4 G)$.

To better characterize the development and origin of the blood supply in the transplants, we performed in vivo imaging of graft vascularization using two-photon microscopy in a complementary series of experiments. For this, two groups of transplanted mice (no-delay and delay groups) were repeatedly imaged to assess the time dependence of blood vessel density, as well as the origin of the vessels in the graft and the surrounding host brain tissue. Dark holes indicating the presence of necrotic areas were most often observed in central areas of the grafts, while cell clusters were present at their periphery (Fig. 5a,b). No obvious correlation was found be- tween the presence of such areas and the amplitude of local vascular densities (Fig. $5 a-d$ ). The average vascular density inside the graft seemed larger in delayed than in nondelayed conditions (no-delay group: $0.24 \pm 0.08, n=8$; delay group, $0.34 \pm 0.08, n=9$; Fig. $5 e$ ), although the difference was not significant, given the high interanimal variability (Fig. $5 e$ ). Interestingly, vessels inside the graft were more swollen and tortuous at $7 \mathrm{dpt}$ in the absence of delay, suggesting the existence of significant inflammation. Yet the most striking differences observed between the two conditions occurred in the vascular composition, which is in agreement with our immunohistochemical results (Fig. 4). While graft vascularization was exclusively composed of host blood vessels in the no-delay condition, it was a mixture of host and donor vessels in the delay condition. Indeed, $\mathrm{GFP}^{+}$donor cells were incorporated into vessel walls as early as $7 \mathrm{dpt}$ (Fig. $5 h-i)$; they assembled into fully formed donor EGFP ${ }^{+}$vessels after 2 weeks (Fig. $5 I-m$ ) and remained in place for at least another month (data not shown). In contrast, in the no-delay group, grafted cells were distant from blood vessels at all times ( 7 and $14 \mathrm{dpt}$; Fig. $5 f, g, j, k)$. 


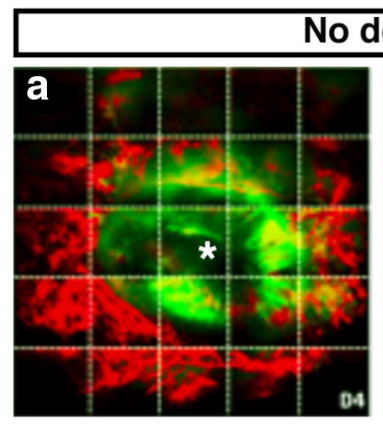

\section{No delay}

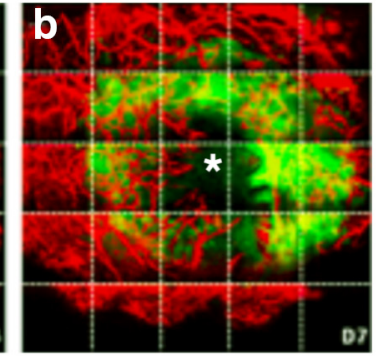

e

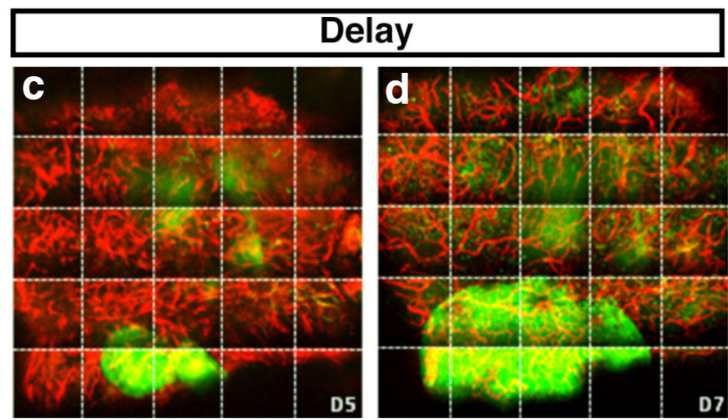

GFP-graft/RhodamineB-blood supply

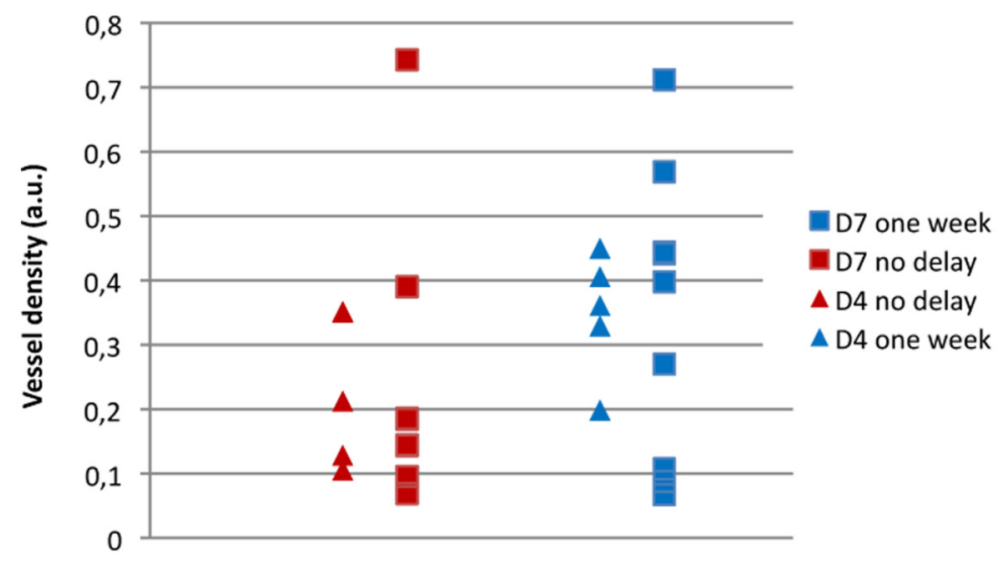

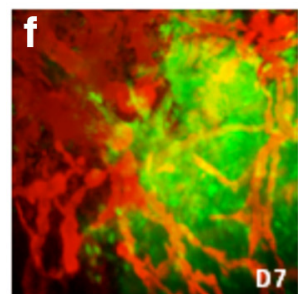
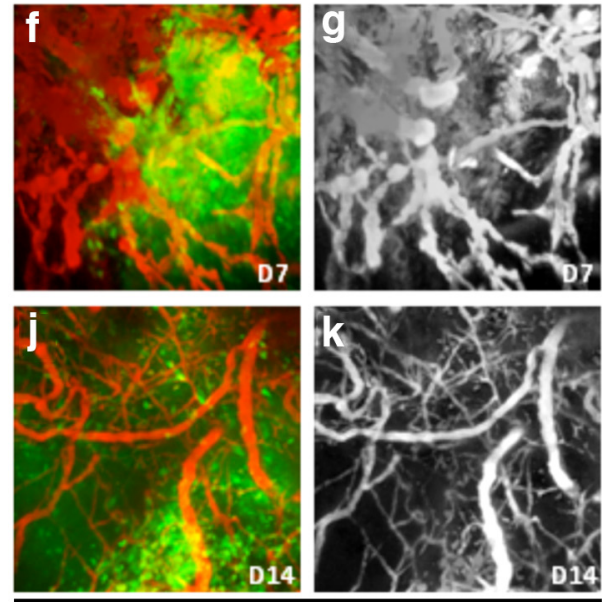

No delay
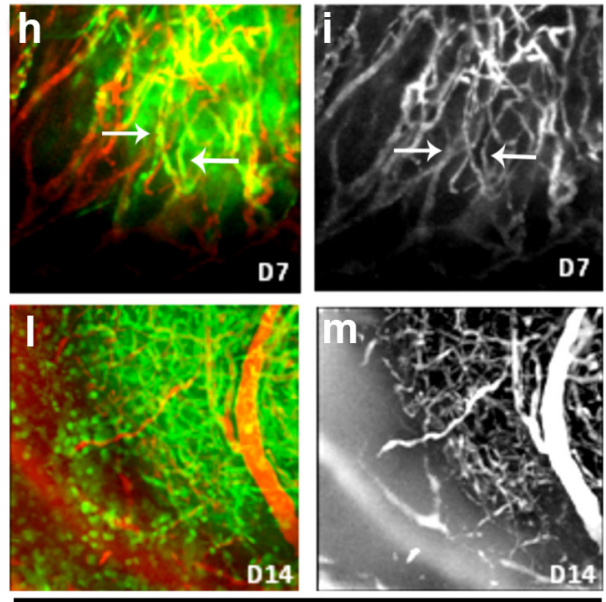

Delay

Figure 5. Dynamic intravital imaging of vascular density inside the transplant. $\boldsymbol{a}-\boldsymbol{d}$, Typical bicolor projection images (grafted cells, green; blood supply, red) from image stacks of the entire glass window over a depth of $400 \mu \mathrm{m}$. Acquisitions were obtained both at 4 and $5 \mathrm{~d}$ (D4/5) and $7 \mathrm{~d}$ (D7) postgrafting at cellular resolution. Dotted squares highlight the typical field of view of the $20 \times$ objective. Twenty-five such fields were stitched together to cover the whole window. Grafting had been performed either without delay $(\boldsymbol{a}, \boldsymbol{b})$ or with a 1 week delay $(\boldsymbol{c}, \boldsymbol{d})$ after cortical lesion. Note that dark holes $\left(^{*}\right)$ corresponding to necrotic regions were often present inside the graft and that green areas were overall similarly vascularized in both conditions. $e$, Plot of vessel densities inside the graft of mice grafted with or without delay and imaged at D4 and D7. Vessel densities were not significantly different between the two conditions ( $p>0.1)$. $f-m$, Bicolor high-resolution images from regions of interest located inside the graft. Corresponding blood vessels are presented separately in gray on each side. $\boldsymbol{f}, \boldsymbol{g}, \boldsymbol{j}, \boldsymbol{k}$, Cells that had been grafted acutely remained away from blood vessels at all times (D7 and D14). $\boldsymbol{h}, \boldsymbol{i}$, Cells that had been grafted with a 1 week delay from the day of cortical lesion were found along blood vessels on D7 (see arrow). $\boldsymbol{I}, \boldsymbol{m}$, At D14, the density of such cells was increased, eventually leading to networks of perfused tubular structures. Vessels were thus at least partially composed of differentiated grafted cells. Scale bars: $\boldsymbol{a}-\boldsymbol{d}, 400 \mu \mathrm{m} ; \boldsymbol{f}-\boldsymbol{m}, 100 \mu \mathrm{m}$.

\section{Axonal projections of transplanted neurons}

We have previously shown that embryonic motor cortical tissue transplanted into the damaged motor cortex of adult mice immediately after cortical lesions send appropriate projections to cortical and subcortical targets of the motor cortex, including long distance targets such as the spinal cord (Gaillard et al., 2004; Gaillard et al., 2007). In the present study, we examined the ax- onal projections of grafted neurons at 4, 7, 14, and $90 \mathrm{dpt}$ in the no-delay and delay groups.

At $4 \mathrm{dpt}$, in the no-delay group $(n=5)$, a few $\mathrm{GFP}^{+}$fibers were identified in the host cortex $\sim 150-250 \mu \mathrm{m}$ away from the graft-host border (Fig. $6 a)$. In the delay group $(n=5)$, the front of $\mathrm{GFP}^{+}$axons found in the cortex was $\sim 500 \mu \mathrm{m}$ away from the graft-host interface (Fig. $6 b$ ). In both groups, trans- 
planted neuronal cell bodies and processes expressed DCX, a marker for immature neuroblasts.

At $7 \mathrm{dpt}$, in the no-delay group $(n=5)$ $\mathrm{GFP}^{+}$fibers left the graft and proceeded toward the underlying corpus collasum (cc) (Fig. $6 c$ ). In the delay group $(n=5)$, a dense contingent of $\mathrm{GFP}^{+}$fibers were found ipsilaterally within the cc and the lateral and medial cortex; in addition, developing axons were found ipsilaterally within the caudate-putamen $(\mathrm{CPu})$ and contralaterally in the cc, the motor cortex, and the $\mathrm{CPu}$ (Fig. $6 d$ ). Most strikingly, at 7 dpt, the density of $\mathrm{GFP}^{+}$axons was considerably higher both ipsilaterally and contralaterally in the cortex and $\mathrm{CPu}$ (see Fig. $8 b$ ) compared with the no-delay group (see Fig. $8 a$ ).

At $14 \mathrm{dpt}$, in the no-delay group $(n=$ 5) $\mathrm{GFP}^{+}$fibers progressed further tangentially in the host cortex. Most of them terminated within the deep cortical layers (Fig. 6e). In addition, $\mathrm{GFP}^{+}$fibers crossed the $\mathrm{cc}$ and entered the $\mathrm{CPu}$ (see Fig. $8 c$ ), and leading axons were found in the internal capsule (ic; Fig. $8 g$ ). In the delay group $(n=5)$, the density of $\mathrm{GFP}^{+}$axons was considerably higher both ipsilaterally and contralaterally in the cortex, $\mathrm{CPu}$, and thalamus (see Fig. 8d,f) compared with the no-delay group (see Fig. $8 c, e$ ). Fastdeveloping fibers were also identified within the thalamus, cerebral peduncle (cp), and, in some cases, at the level of pontine nuclei (Pn).

At $90 \mathrm{dpt}$, in the no-delay group $(n=5)$ a dense array of $\mathrm{GFP}^{+}$fibers was found both ipsilaterally and contralaterally within motor and sensorimotor cortices, and mainly ipsilaterally within the dorsolateral $\mathrm{CPu}$ (Figs. $6 g, 7 A, 8 i$ ). This corresponds to the normal pattern of projection of motor cortex neurons, as we previously described (Gaillard et al., 2007). In addition, $\mathrm{GFP}^{+}$fibers were present, in the contralateral cc and host thalamus; especially within the ventrolateral thalamic nuclei (Figs. $7 B, 8 k$ ), ic, Pc, and $\mathrm{Pn}$; and in onethird of animals, in the spinal cord (Fig. $7 B$, Fig. $8 m$ ). At the same time point in the delay group $(n=8), \mathrm{GFP}^{+}$fibers were found in the same areas as in the no-delay group but with a higher density (Figs. 6h, $7,8 j, l, n)$. Strikingly, and contrasting with the absence of $\mathrm{GFP}^{+}$fibers in the spinal cord in two-thirds of the animals in the no-delay group, $\mathrm{GFP}^{+}$fibers were found within the spinal cord in all animals in the delay group (Fig. 8n).

One of the most notable findings of this study is that a delay between cortical lesions and transplantation increased the density of projections developed by transplanted neurons toward
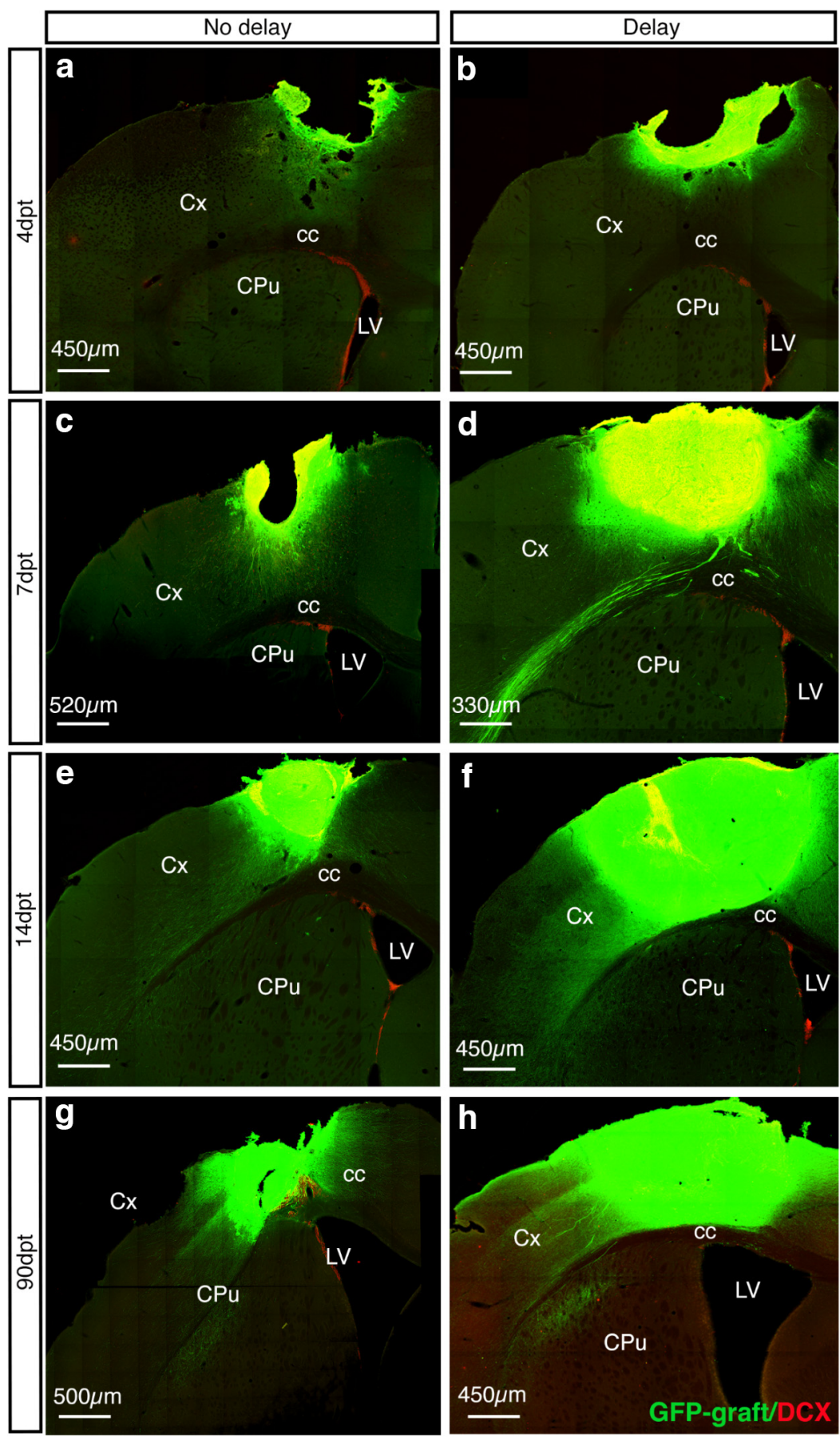

Figure 6. Developmental time course and growth characteristics of graft projections. $\boldsymbol{a}-\boldsymbol{h}$, Confocal photomicrographs of coronal sections showing GFP ${ }^{+}$(green) transplants and their axonal projections. $\boldsymbol{a}, \boldsymbol{b}$, Four days after grafting, the transplanted cortical embryonic neuroblasts coexpressing DCX (red) extend axons toward the adjacent host cortex. $\boldsymbol{c}, \boldsymbol{d}$, Seven days after grafting, transplanted neuroblasts coexpressing DCX (red) extend numerous axons toward the host ispilateral motor cortex. $c$, When transplantation is performed immediately after the cortical lesion, few isolated GFP ${ }^{+}$fibers are found in the underlying corpus callosum. $\boldsymbol{d}$, When transplantation is performed 1 week after the cortical lesion, a dense array of GFP ${ }^{+}$bundles of fibers extended through the underlying corpus callosum to reach subcortical targets such as the ipsilateral striatum and/or the contralateral cortex. $\boldsymbol{e}-\boldsymbol{h}$, Fourteen days $(\boldsymbol{e}, \boldsymbol{f})$ and $90 \mathrm{~d}(\boldsymbol{g}, \boldsymbol{h})$ after grafting numerous GFP ${ }^{+}$fibers are found in the adjacent cortex, corpus callosum, and CPu. Note that for all motor cortex targets at all time points, the number of fibers is dramatically increased when the transplantation is performed 1 week after the cortical lesion $(\boldsymbol{b}, \boldsymbol{d}, \boldsymbol{f}, \boldsymbol{h})$ compared with the no-delay group $(\boldsymbol{a}, \boldsymbol{c}, \boldsymbol{e}, \boldsymbol{g})$. C , Cortex; $\mathrm{LV}$, lateral ventricle. Scale bars: $\boldsymbol{a}, \boldsymbol{b}, \boldsymbol{e}, \boldsymbol{f}, \boldsymbol{h}, 450 \mu \mathrm{m} ; \boldsymbol{c}, 520 \mu \mathrm{m} ; \boldsymbol{d}, 330 \mu \mathrm{m} ; \boldsymbol{g}, 500 \mu \mathrm{m}$.

most of the host motor cortex cortical and subcortical-specific targets.

Rare individual fibers were observed in nontarget areas such as the septum and hippocampus both in the no-delay and delay groups. 
A

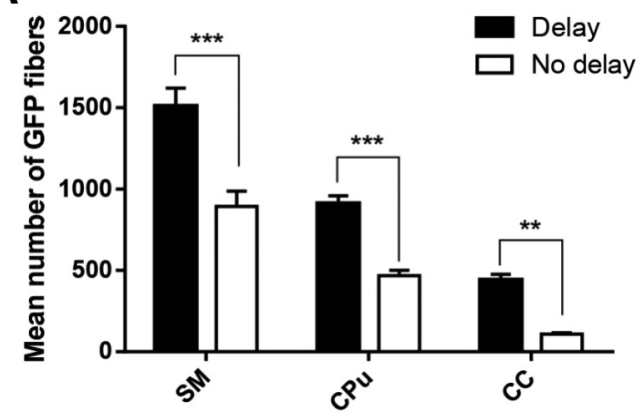

B

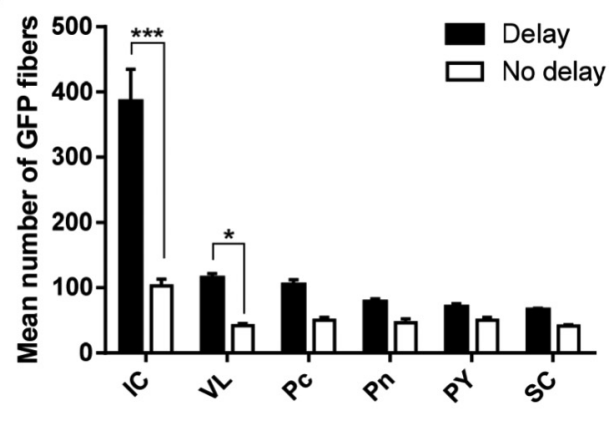

Figure 7. Mean number of GFP-labeled fibers in the delay and the no-delay condition $90 \mathrm{~d}$ after transplantation. For each group, fiber-labeling indexes were obtained by calculating the mean \pm SD total number of labeled fibers in each region. $\boldsymbol{A}$, Fiber number in ipsilateral sensorimotor (SM) cortex, $\mathrm{CPu}$, and cc. $\boldsymbol{B}$, Fiber number in the ic, ventrolateral thalamic nucleus (VL), cerebral peduncle (Pc), pyramidal tract (PY), and spinal cord (SC). Comparison among groups was performed using two-way ANOVA $\left(F_{(1,24)}=74.72, p<0.0001, A ; F_{(1,45)}=72.48, p<0.0001, B\right)$ followed by $p 0 s t$ hoc comparison using Sidak's multiple-comparisons tests: delay vs no-delay for each structure. ${ }^{*} p<0.05 ;{ }^{* *} p<0.01 ;{ }^{* * *} p<0.001$.

\section{Functional recovery}

Intracortical microstimulation

Using in vivo intracortical microstimulation, we investigated the functional outcome of embryonic motor cortical grafts in the motor cortex of mice transplanted immediately or a week after cortical lesion.

Electrical stimulation using a concentric bipolar electrode (SNEX-100; stimulation intensity, $1.2 \pm 0.16 \mathrm{~mA}$; duration, 0.5 ms) was performed in the motor cortex of control animals $(n=$ 9) as well as in the grafts from both groups (no-delay group, $n=$ 5; delay group, $n=6$ ) at $90 \mathrm{dpt}$ to evoke motor responses. To make sure that the responses observed after graft stimulation were not due to a direct stimulation of the host tissue, we controlled for the diffusion of current (data not shown). To this end, we measured the range of current diffusion in the brain by lowering a recording electrode in the vicinity of the stimulating electrode. We then recorded at different distances from the stimulating electrode the amplitude of current evoked by an electrical stimulation $(10 \mathrm{~mA})$. We observed a rapid decrease in the amplitude of electrical current spreading around the stimulation point, and this current became undetectable at $200 \mu \mathrm{m}$ away from the stimulating electrode. All of the following experiments were conducted using stimulation intensities $<1.5 \mathrm{~mA}$, and all responses to stimulations performed closer than $250 \mu \mathrm{m}$ from the graft borders were excluded from the study.

All mice from the control group exhibited motor responses following electrical stimulation. Five of six mice from the delay group and four of five mice from the no-delay group responded to electrical stimulation with such motor responses.

We investigated the threshold of current intensity required to observe a motor response in control mice and grafted mice with or without delay (Fig. 9). In grafted mice, threshold measurements were determined in both the graft (ipsilateral) and the motor cortex contralateral to the graft (contralateral; Fig. 9a,b). Stimulation thresholds required to observe a motor response were significantly higher for graft stimulations in both the nodelay group $(2.06 \pm 1.08 \mathrm{~mA})$ and the delay group $(1.82 \pm 0.88$ $\mathrm{mA}$ ) than for motor cortex stimulation in control mice (KruskalWallis test, $p=0.0002$ ) (Fig. 9c).

We then evaluated the optimal stimulation depth within the graft able to evoke movement (Fig. 9d). In both the delay and no-delay groups, the threshold increased as the stimulation electrode got closer to the surface of the graft. The stimulation was significantly more efficient at depths $<700 \mu \mathrm{m}$ under the graft surface (two-way ANOVA, $F_{(4,60)}=13.56, p<0.001$ ). This sug- gests that grafted neurons localized in the deepest part of the graft are more efficient in inducing motor responses.

The type of movements evoked by motor cortex stimulation was investigated in nine intact control mice and in mice grafted with or without a delay, and a cortical map of motor responses was established (Fig. 9, Table 1). Although the size of the transplant did not allow for precise mapping of motor responses, the movements evoked were largely specific, since the majority of movements observed corresponded to expected limb movements (Fig. 9, Table 1). Overall, our results showed that transplants in both the no-delay and delay groups induced functional motor responses in adult mice.

\section{Behavioral study}

Lesions of the forelimb representation area of the motor cortex produce skilled forelimb-reaching deficits. We assessed the functional deficits induced by the lesion and whether cortical grafts with or without delay could mediate sustained motor function recovery. For this, we evaluated skilled reaching abilities using the staircase test in four groups of animals (control, $n=10$; lesions, $n=12$; transplanted without delay, $n=12$; transplanted with a 1 week delay, $n=13$ ). The staircase test is considered to be the gold standard to analyze such deficits, as also previously used to assess motor impairment (Baird et al., 2001). The number of sucrose pellets collected with the forepaw affected by the lesion/transplantation procedure (i.e., the contralateral paw) was recorded before lesion and/or transplantation and during 12 postoperative weeks, and was defined as the contralateral forepaw performance. We first evaluated how contralateral forepaw performance within each group evolved with time by comparing it with baseline performance at different postoperative times (1-12 weeks; Fig. 10a). As expected, in the control group, contralateral forepaw performance was stable over time and was not significantly different from baseline (Fig. 10a). In contrast, the contralateral forepaw performance in the lesion group was significantly impaired compared with baseline at all postoperative weeks (Fig. 10a). Interestingly, in both transplanted groups, after an initial period of deficits comparable with those observed in the lesion group, contralateral forepaw performance returned to baseline levels (Fig. $10 a)$. Based on these observations, we analyzed the effects of lesion or grafting by comparing the contralateral forepaw performance among the four experimental groups over the two relevant time periods from week 2 to 7 and from week 8 to 12 . During the first time period (week 2 to 7 ), the contralateral forepaw performance in all three lesion or transplanted groups was significantly 
different from the control group (control vs lesion, $p<0,0001$; control vs no-delay, $p=0,0038$; control vs delay, $p<0.0001$ ); no significant differences were observed among the three groups, lesion or transplanted (lesion vs no-delay, $p=0.1711$; lesion vs delay, $p=0.8544$; no-delay vs delay, $p=0.2235)$. During the second time period, only the lesion group showed significantly reduced contralateral performance compared with the control group (control vs lesion, $p=0.0065$; control vs no-delay, $p=0.3209$; control vs delay, $p=0.3747$; Fig. 10b). More interestingly, among the three groups, lesion or transplanted, the only significant difference observed was between the lesion group and the delay group (lesion vs no-delay, $p=0.0578$; lesion vs delay, $p=0.0399$; no-delay vs delay, $p=0.8960$; Fig. $10 b$ ). Altogether, our results demonstrate the beneficial effects of grafted neurons on functional motor recovery and indicate that graft-mediated functional recovery is increased when transplantation is performed 1 week after the lesion.

\section{Discussion}

The present study was performed to determine the effects of a delay between adult motor cortical lesion and transplantation.

Our data show that introducing a 1 week delay between the time of the lesion and transplantation (1) enhances the transplant size through increased cell proliferation, (2) affects the origin of blood vessels supplying the graft, (3) dramatically increases the density of projections developed by grafted neurons toward appropriate cortical and subcortical targets, and (4) enhances the functional recovery of motor skills by grafts.

\section{Graft survival}

It was previously reported that delaying transplantation following lesion ameliorated the graft survival rate (Kesslak et al., 1986; Miyoshi et al., 1995b). In the present study, the combination of GFP to detect the grafted cells, BrdU incorporation to detect cell proliferation, and TUNEL staining to detect cell death allowed us to unambiguously show that a delay between lesion and transplantation significantly increased the proliferation of grafted cells without significantly modifying apoptosis. The accumulation of neurotrophic activity at the site of lesion has been proposed to promote transplant survival. Accordingly, striatal cholinergic grafts implanted 3-6 d after retrohippocampal lesion showed improved survival (Manthorpe et al., 1983); similarly, the survival of transplant is enhanced by extracts prepared from injured brain (Nieto-Sampedro et al., 1984). A detailed analysis of growth factors and the time course of their release in each condition is necessary to determine the molecular basis for the present results. It would also be interesting to study postlesional inflammation
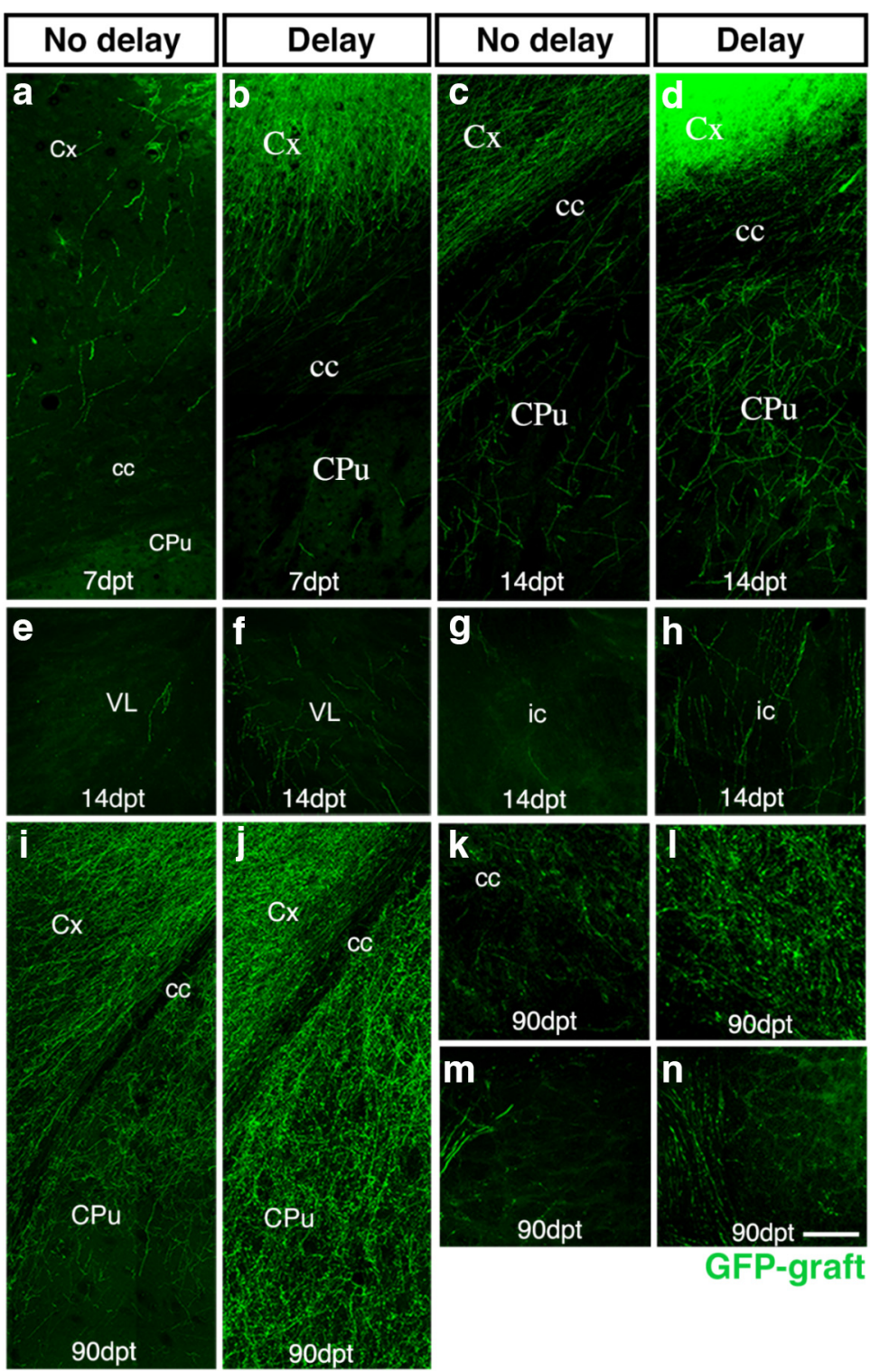

Figure 8. Axonal projections developed by transplanted neurons toward the cortical and subcortical motor cortex targets. $\boldsymbol{a}-\boldsymbol{f}$, $\boldsymbol{h}-\boldsymbol{I}$, High-magnification confocal photomicrographs of coronal sections showing GFP ${ }^{+}$grafted neurons projections toward the delay $(\boldsymbol{a}, \boldsymbol{c}, \boldsymbol{e}, \boldsymbol{g}, \boldsymbol{i}, \boldsymbol{k})$ or with delay $(\boldsymbol{b}, \boldsymbol{d}, \boldsymbol{f}, \boldsymbol{h}, \boldsymbol{j}, \boldsymbol{l})$ after motor cortex lesion. $\boldsymbol{e}-\boldsymbol{h}, \boldsymbol{k}-\boldsymbol{n}, \mathrm{At} 14 \mathrm{~d}$ postgrafting, GFP ${ }^{+}$fibers appeared in distant subcortical motor cortex targets, such as the thalamus $(\boldsymbol{e}, \boldsymbol{f}, \boldsymbol{k}, \boldsymbol{I})$ and the internal capsule $(\boldsymbol{g}, \boldsymbol{h})$, and they reached the strikingly increased when transplantation was performed 1 week after the cortical lesion $(\boldsymbol{b}, \boldsymbol{d}, \boldsymbol{f}, \boldsymbol{h}, \boldsymbol{j}, \boldsymbol{I}, \boldsymbol{n})$ compared with the no-delay group $(\boldsymbol{a}, \boldsymbol{c}, \boldsymbol{e}, \boldsymbol{g}, \boldsymbol{i}, \boldsymbol{k}, \boldsymbol{m})$. Cx, Cortex; VL, ventrolateral thalamic nuclei. Scale bars: $\boldsymbol{a}-\boldsymbol{d}, \boldsymbol{i}, \boldsymbol{j}, 90 \mu \mathrm{m} ; \boldsymbol{e}-\boldsymbol{h}, \boldsymbol{k}-\boldsymbol{n}, 120 \mu \mathrm{m}$.

and its beneficial or deleterious effects on the angiogenic process, survival, and the projections developed by the grafted neurons in each condition.

\section{Graft vascularization}

The importance of functional vascularization for the survival and development of transplants was highlighted more than 3 decades ago. For instance, cell survival of transplanted neurons can be improved when grafts are placed in highly vascularized areas of the host such as the anterior eye chamber (Olson et al., 1982) or the median eminence (Rosenstein and Brightman, 1978). Additional evidence connects the enhancement of vascularization with the improvement of graft survival (Finger and Dunnett, 1989; Casper et al., 2003) and graft expansion (Finger and Dun- 
a
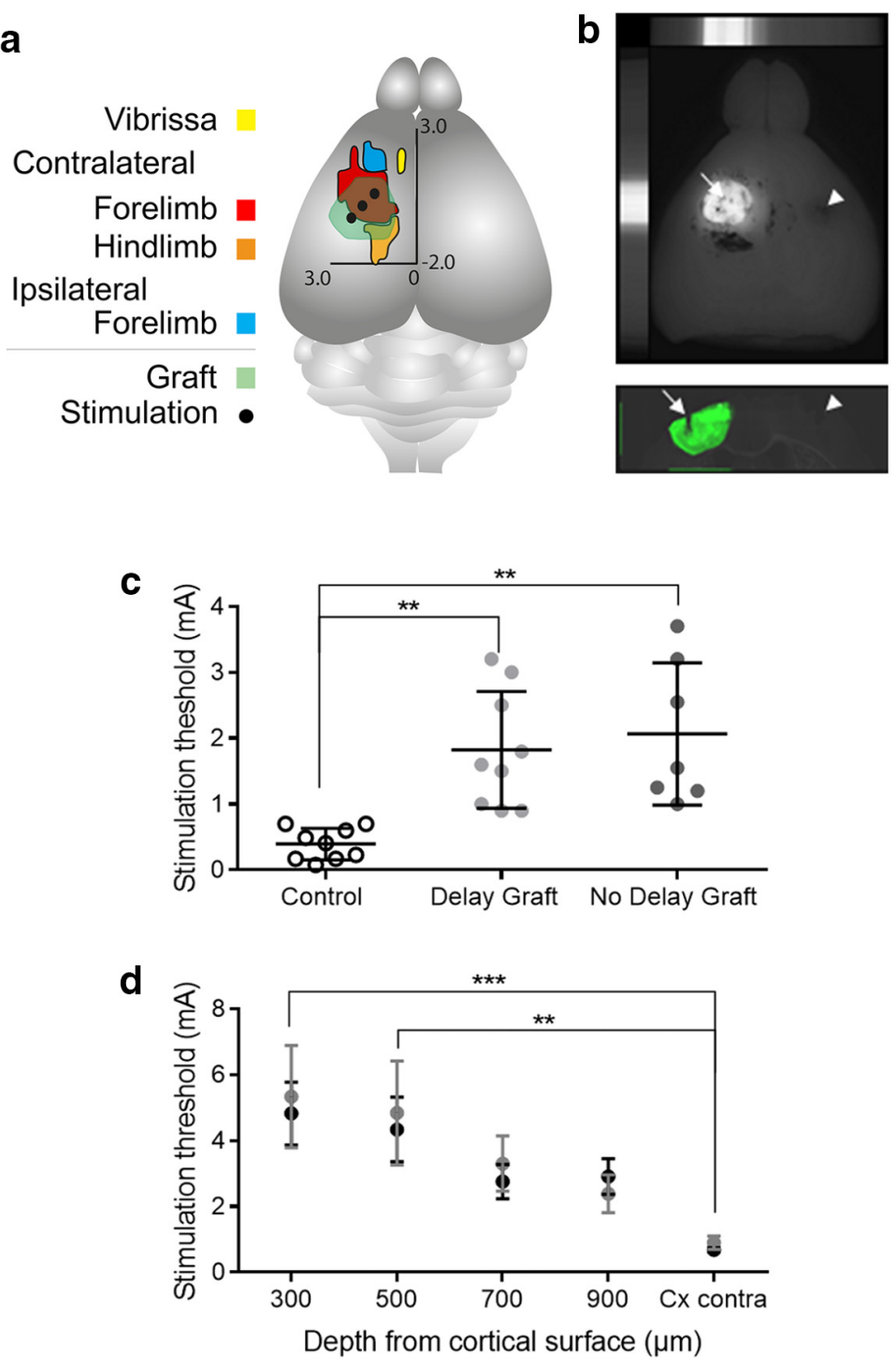

- Graft No Delay - Graft Delay

Figure 9. Functional mapping of the motor cortex in control and grafted mice. $\boldsymbol{a}$, Schematic representation of the dorsal surface of the mouse cortex showing the result of the mapping experiments conducted in control animals. The green region represents the localization of one graft from the delay group (also shown in $\boldsymbol{b}$ ), and black dots represent the stimulation location inside this graft. $\boldsymbol{b}$, Example of a delayed graft (schematized in $\boldsymbol{a}$ ); the top panel shows the whole brain surface containing the graft (white region), and the bottom panel represents a coronal section of the brain containing the graft (green). Arrows and arrowheads indicate a stimulation location in the graft and in the motor cortex contralateral to the graft, respectively. c, Stimulation thresholds evoking a movement in control motor cortex (white circles), delay grafts (gray circles), and no-delay grafts (dark circles). Both grafted groups exhibit motor responses to stimulation of the graft, but both required a stimulation intensity higher than that in control animals. $\boldsymbol{d}$, Stimulation thresholds evoking a motor response at different depths under the graft surface compared with the stimulation threshold observed in intact motor cortex ( $(x$ contra) from the same animals at a depth of $900 \mu \mathrm{m}$ below the cortical surface. Both the delay group (gray circles) and the no-delay group (dark circles) exhibit a more efficient motor response to stimulations performed in the deep layer of the graft. $c$, Data are presented as the mean $\pm S E M$, Kruskal-Wallis; ${ }^{* *} p<0.001$. $\boldsymbol{d}$, Two-way ANOVA, $F_{(4,60)}=13.56, p<0.0001$ followed by Bonferroni's test; ${ }^{* *} p<0.001$; ${ }^{* * *} p<0.0001$.

Here, the graft vasculature was examined in vivo by biphoton microscopy that detects functional vessels after the injection of dye and on brain sections by CD31 immunostaining that detect all endothelial cells, and was quantified at different time points after the transplantation. Quantification of CD31 immunostained blood vessels in the $\mathrm{GFP}^{+}$grafts showed that a delay between lesion and transplantation led to a transient but significant increase in graft vascularization $4 \mathrm{~d}$ after transplantation. In addition, delaying transplantation influences the origin of the blood vessels present in the transplant in favor of a mixed graft/host origin versus a primarily host origin for grafts introduced immediately after the lesion. Hence, progenitors with the potential to become endothelial cells that are present in the graft receive adequate survival and/or angiogenic stimuli in the delayed grafting schedule. Vascular endothelial growth factor whose expression by early activated microglia/macrophages culminate 3-6 d following traumatic brain injury (Giulian et al., 1989; Bartholdi et al., 1997; Nag et al., 1997, 2002; Sköld et al., 2005) is likely to play an active role in this process. Our observations also support the close coupling of angiogenesis and neurogenesis occurring during brain development (Lok et al., 2007; Teng et al., 2008), and, possibly, the enhanced graft-derived vascularization improves transplant growth. Importantly, by demonstrating a significant participation of graft endothelial cells to neovascularization of the transplant, our findings raise the question of the potential of stem cell-derived neurons to efficiently integrate and survive into areas of lesions or degenerated brain areas, in the absence of grafted endothelial cells.

\section{Axonal projections of transplanted neurons}

The potential effectiveness of neural repair through transplantation depends on the level of reconstruction of damaged pathways (Wictorin et al., 1990). In the cerebral cortex, point-to-point innervation of target areas by the transplant neurons is critical. We have previously shown that embryonic motor cortical neurons

nett, 1989). It is likely that a delay between lesion and transplantation promotes the development of blood vessels and offers a favorable/permissive condition for graft survival. Indeed, $4 \mathrm{~d}$ following cortical lesions, an increase in vascular density around the lesion cavity was reported (Miyoshi et al., 1995a,b). However, no information was available as to the contribution of host versus transplant elements in this vascularization phenomenon and to what extent it was influenced by a delay between the lesion and transplantation. transplanted immediately into damaged motor cortex of adult mice develop appropriate cortical and subcortical projections (Gaillard et al., 2007). In the present study, we extend this observation by showing that a 1 week delay in transplantation dramatically increased the axonal projections developed by grafted neurons. More importantly, in all delayed transplantation, grafted neurons extended axons over remarkably long distances reaching the spinal cord, which was seldom the case when transplantation was performed immediately after lesion. 
Functional integration and recovery

A key question regarding the effectiveness of cell replacement therapies in the brain is the integration of new neurons into existing circuits. Functional integration of embryonic motor cortical neurons transplanted in the damaged adult rat cortex has been reported using patch-clamp recording on brain slices (SantosTorres et al., 2009) and single-cell activity recording in vivo (Neafsey et al., 1989; Senatorov et al., 1991) or by measurement of local cerebral glucose utilization (Ebrahimi-Gaillard et al., 1995). Here, we used a challenging electrophysiological technique to evaluate the integration of transplanted neurons and the long-term assessment of motor function recovery using a gold standard behavioral test. Along with anatomical evidence of graft integration, we show that neurons transplanted with or without a delay are functionally integrated into host circuitry and are capable of initiating appropriate movements after electrical stimulation. In addition, we observed that the deepest part of the transplants was more sensitive to electrical stimulation. Interestingly, we recently demonstrated that grafted neurons expressing Ctip2, a marker for subcortically projecting cortical neurons, preferentially settle in deep parts of the grafts (Ballout et al., 2016). Similarly, appropriate graft organization and highly specific graft integration were reported after transplantation of embryonic cortical progenitors in the ablated cortical layer 2/3 (Falkner et al., 2016). Our experiments did not allow us to determine whether the movements evoked by electrical stimulation of grafted neurons resulted from their projections to long distance targets or whether a relay with host neurons is required. However, such complete responses mediated by transplanted neurons reflect high levels of functional integration, connectivity, and synaptic integration as well as appropriate neurotransmitter release.

At the behavioral level, lesions of the forelimb representation area of the motor cortex produce skilled forelimb-reaching deficits. Data on the functional outcome of embryonic cell transplantation following cerebral cortex lesions in adult rats are equivocal. For instance, Plumet et al. (1993) have shown that motor cortex grafts induced partial reduction of deficit in skilled forelimb reaching. In contrast, Kolb et al. $(1988,1994)$ did not observe any behavioral recovery after frontal cortex grafts. One caveat in these studies is that none of them document whether the anatomical repair had been achieved.

Our results show a forelimb deficit in the limb contralateral to the injury in the lesion group during entire period of testing. Animals receiving a graft of embryonic tissue with or without delay showed an initial reduction of the performance of the affected paw followed by a sustained recovery. This functional recovery was significantly better for animals transplanted with a delay. The capacity of the graft to induce recovery of lost func-
Table 1. Movements evoked by intracortical microstimulation

\begin{tabular}{lccc}
\hline & Control & No-delay graft & Delay graft \\
\hline $\begin{array}{l}\text { Motor responses } \\
\text { Movements representations }\end{array}$ & $100 \%$ & $80 \%$ & $83.3 \%$ \\
Forelimb & & & \\
Hindlimb & $73 \%$ & $29 \%$ & $11 \%$ \\
Vibrissa & $24 \%$ & $71 \%$ & $78 \%$ \\
Tail & $3 \%$ & $0 \%$ & $0 \%$ \\
\hline
\end{tabular}

Note that electrical stimulation induced overall appropriate motor responses in both transplantation groups, although the sensitivity of grafted cells to electrical stimuli is reduced, particularly in the upper part of the transplants.
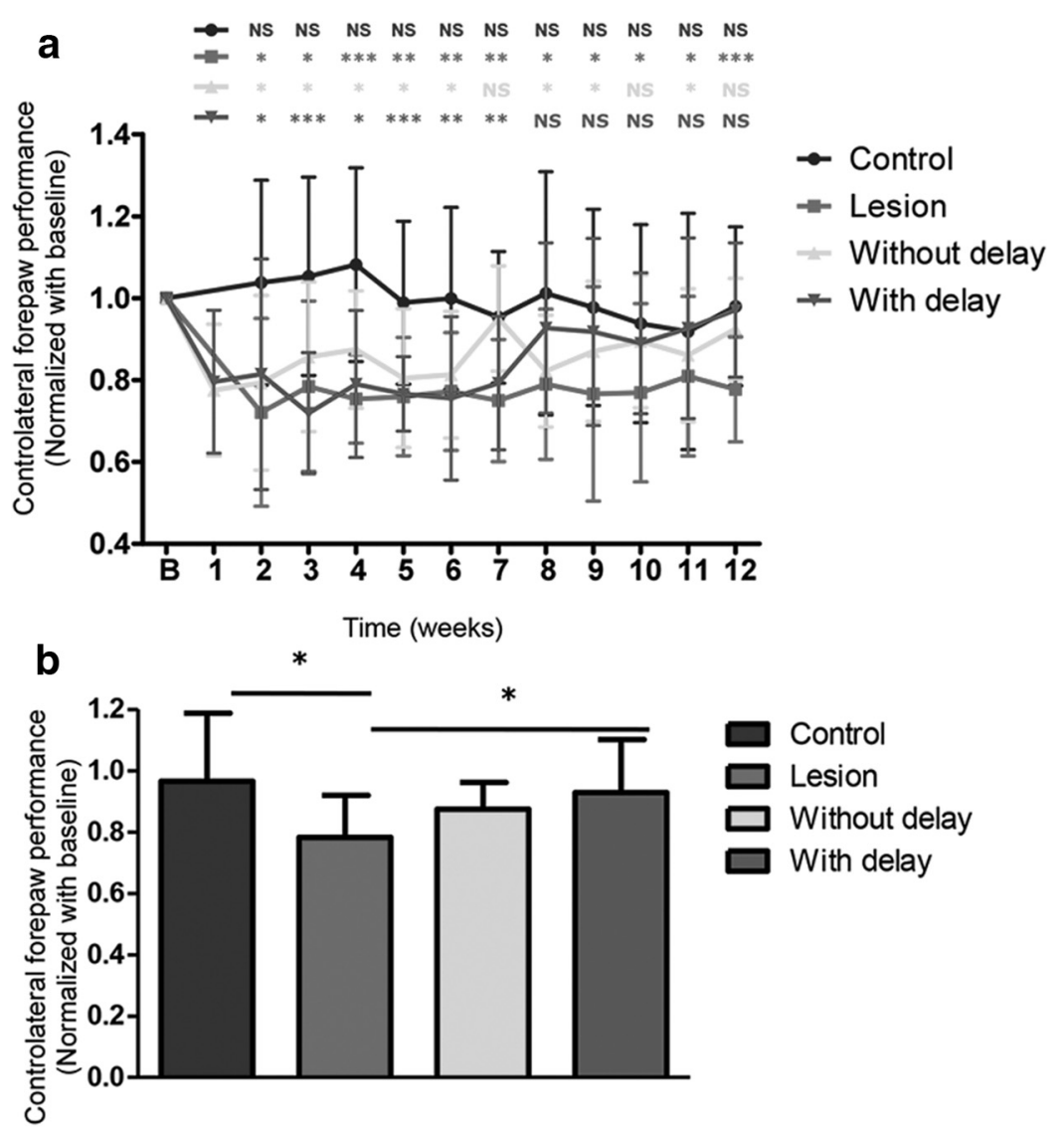

Figure 10. Staircase test performance. $\boldsymbol{a}$, Contralateral forepaw performance at the preoperative baseline sessions and during 12 postoperative weeks. While lesioned animals never reached preoperative performance levels, transplantation and, to a greater extent, delayed transplantation rescued performance to baseline levels during the last month of testing. Data are presented as the mean $\pm S D$, and an asterisk indicates a difference compared with the baseline performance within each experimental group. NS, performance during the third postoperative month. Delayed transplantation promotes the recovery of skilled forelimb abilities. Data are presented as the mean $\pm S D$, and the asterisk indicates a difference between groups. Two-way repeated-measures ANOVA followed by Fisher's PLSD, ${ }^{* * *} p<0.0001 ;{ }^{* *} p<0.001 ;{ }^{*} p<0.05$.

tions depends mainly on the formation of connections between transplanted neurons and host (Björklund and Stenevi, 1979; Björklund et al., 1980; Gaillard et al., 2009; Gaillard and Jaber, 2011). In accordance with these findings, we observed a larger number of axonal projections when transplantation was performed with a delay. In addition, as previously shown (Gaillard et al., 2007), axons developed by embryonic cortical neurons reach their more distant cortical targets 6 weeks after transplantation, a time that matches with the observed behavioral benefits. This strongly suggests that the axonal repair of the damaged pathways by the transplanted neurons is indeed of primary importance to ensure functional recovery. It does not exclude that functional recovery might also be improved by trophic or neuroprotective 
effects of the grafted cells on host neurons (Ourednik et al., 2002). Additionally, combining transplantation with other approaches such as postoperative training (Mayer et al., 1992; Riolobos et al., 2001) or remote control of grafted neurons activity (Chen et al., 2016) could further improve functional recovery.

Together, our results show that introducing a delay between the lesion and transplantation significantly enhances graft vascularization, survival, and the establishment of transplant-to-host projections. They also indicate that endothelial cells originating from the graft are beneficial for a better graft survival. Strikingly, transplanted cortical neurons show unexpected levels of functional integration, especially when transplantation is performed 1 week after the lesion. These findings open new avenues in cell transplantation strategies as they indicate successful brain repair may occur following delayed transplantation.

\section{References}

Baird AL, Meldrum A, Dunnett SB (2001) The staircase test of skilled reaching in mice. Brain Res Bull 54:243-250. CrossRef Medline

Ballout N, Frappé I, Péron S, Jaber M, Zibara K, Gaillard A (2016) Development and maturation of embryonic cortical neurons grafted into the damaged adult motor cortex. Front Neural Circuits 10:55. CrossRef Medline

Bartholdi D, Rubin BP, Schwab ME (1997) VEGF mRNA induction correlates with changes in the vascular architecture upon spinal cord damage in the rat. Eur J Neurosci 9:2549-2560. CrossRef Medline

Bessert DA, Skoff RP (1999) High-resolution in situ hybridization and TUNEL staining with free-floating brain sections. J Histochem Cytochem 47:693-702. CrossRef Medline

Björklund A, Stenevi U (1979) Reconstruction of the nigrostriatal dopamine pathway by intracerebral nigral transplants. Brain Res 177:555-560. CrossRef Medline

Björklund A, Dunnett SB, Stenevi U, Lewis ME, Iversen SD (1980) Reinnervation of the denervated striatum by substantia nigra transplants: functional consequences as revealed by pharmacological and sensorimotor testing. Brain Res 199:307-333. CrossRef Medline

Bouët V, Freret T, Toutain J, Divoux D, Boulouard M, Schumann-Bard P (2007) Sensorimotor and cognitive deficits after transient middle cerebral artery occlusion in the mouse. Exp Neurol 203:555-567. CrossRef Medline

Burda JE, Bernstein AM, Sofroniew MV (2016) Astrocyte roles in traumatic brain injury. Exp Neurol 275:305-315. CrossRef Medline

Casper D, Finkelstein E, Goldstein IM, Palencia D, Yunger Y, Pidel A (2003) Dopaminergic neurons associate with blood vessels in neural transplants. Exp Neurol 184:785-793. CrossRef Medline

Chen Y, Xiong M, Dong Y, Haberman A, Cao J, Liu H, Zhou W, Zhang SC (2016) Chemical control of grafted PSC-derived neurons in a mouse model of Parkinson's disease. Cell Stem Cell 18:817-826. CrossRef Medline

Ebrahimi-Gaillard A, Beck T, Gaillard F, Wree A, Roger M (1995) Transplants of embryonic cortical tissue placed in the previously damaged frontal cortex of adult rats: local cerebral glucose utilization following execution of forelimb movements. Neuroscience 64:49-60. CrossRef Medline

Falkner S, Grade S, Dimou L, Conzelmann KK, Bonhoeffer T, Götz M, Hübener M (2016) Transplanted embryonic neurons integrate into adult neocortical circuits. Nature 539:248-253. CrossRef Medline

Fenrich KK, Weber P, Hocine M, Zalc M, Rougon G, Debarbieux F (2012) Long-term in vivo imaging of normal and pathological mouse spinal cord with subcellular resolution using implanted glass windows. J Physiol 590: 3665-3675. CrossRef Medline

Finger S, Dunnett SB (1989) Nimodipine enhances growth and vascularization of neural grafts. Exp Neurol 104:1-9. CrossRef Medline

Gadani SP, Walsh JT, Lukens JR, Kipnis J (2015) Dealing with danger in the CNS: the response of the immune system to injury. Neuron 87:47-62. CrossRef Medline

Gaillard A, Jaber M (2007) Is the outgrowth of transplant-derived axons guided by host astrocytes and myelin loss? Cell Adh Migr 1:161-164. CrossRef Medline
Gaillard A, Jaber M (2011) Rewiring the brain with cell transplantation in Parkinson's disease. Trends Neurosci 34:124-133. CrossRef Medline

Gaillard A, Roger M (2000) Early commitment of embryonic neocortical cells to develop area-specific thalamic connections. Cereb Cortex 10:443453. CrossRef Medline

Gaillard A, Gaillard F, Roger M (1998) Neocortical grafting to newborn and adult rats: developmental, anatomical and functional aspects. Adv Anat Embryol Cell Biol 148:1-86. CrossRef Medline

Gaillard A, Prestoz L, Dumartin B, Cantereau A, Morel F, Roger M, Jaber M (2007) Reestablishment of damaged adult motor pathways by grafted embryonic cortical neurons. Nat Neurosci 10:1294-1299. CrossRef Medline

Gaillard A, Decressac M, Frappé I, Fernagut PO, Prestoz L, Besnard S, Jaber M (2009) Anatomical and functional reconstruction of the nigrostriatal pathway by intranigral transplants. Neurobiol Dis 35:477-488. CrossRef Medline

Gaillard F, Domballe L, Gaillard A (2004) Fetal cortical allografts project massively through the adult cortex. Neuroscience 126:631-637. CrossRef Medline

Gaspard N, Bouschet T, Hourez R, Dimidschstein J, Naeije G, van den Ameele J, Espuny-Camacho I, Herpoel A, Passante L, Schiffmann SN, Gaillard A, Vanderhaeghen P (2008) An intrinsic mechanism of corticogenesis from embryonic stem cells. Nature 455:351-357. CrossRef Medline

Gaspard N, Gaillard A, Vanderhaeghen P (2009) Making cortex in a dish: in vitro corticopoiesis from embryonic stem cells. Cell Cycle 8:2491-2496. CrossRef Medline

Giulian D, Chen J, Ingeman JE, George JK, Noponen M (1989) The role of mononuclear phagocytes in wound healing after traumatic injury to adult mammalian brain. J Neurosci 9:4416-4429. Medline

Harris NG, Mironova YA, Hovda DA, Sutton RL (2010) Chondroitinase $\mathrm{ABC}$ enhances pericontusion axonal sprouting but does not confer robust improvements in behavioral recovery. J Neurotrauma 27:1971-1982. CrossRef Medline

Kesslak JP, Brown L, Steichen C, Cotman CW (1986) Adult and embryonic frontal cortex transplants after frontal cortex ablation enhance recovery on a reinforced alternation task. Exp Neurol 94:615-626. CrossRef Medline

Kolb B, Reynolds B, Fantie B (1988) Frontal cortex grafts have opposite effects at different postoperative recovery times. Behav Neural Biol 50: 193-206. CrossRef Medline

Kolb B, Muirhead D, Cioe J (1994) Neonatal frontal cortex grafts fail to attenuate behavioural deficits or abnormal cortical morphogenesis. Brain Res 647:15-22. CrossRef Medline

Lok J, Gupta P, Guo S, Kim WJ, Whalen MJ, van Leyen K, Lo EH (2007) Cell-cell signaling in the neurovascular unit. Neurochem Res 32:20322045. CrossRef Medline

Lu P, Wang Y, Graham L, McHale K, Gao M, Wu D, Brock J, Blesch A, Rosenzweig ES, Havton LA, Zheng B, Conner JM, Marsala M, Tuszynski MH (2012) Long-distance growth and connectivity of neural stem cells after severe spinal cord injury. Cell 150:1264-1273. CrossRef Medline

Manthorpe M, Nieto-Sampedro M, Skaper SD, Lewis ER, Barbin G, Longo FM, Cotman CW, Varon S (1983) Neuronotrophic activity in brain wounds of the developing rat. Correlation with implant survival in the wound cavity. Brain Res 267:47-56. CrossRef Medline

Mayer E, Brown VJ, Dunnett SB, Robbins TW (1992) Striatal graftassociated recovery of a lesion-induced performance deficit in the rat requires learning to use the transplant. Eur J Neurosci 4:119-126. CrossRef Medline

Michelsen KA, Acosta-Verdugo S, Benoit-Marand M, Espuny-Camacho I, Gaspard N, Saha B, Gaillard A, Vanderhaeghen P (2015) Area-specific reestablishment of damaged circuits in the adult cerebral cortex by cortical neurons derived from mouse embryonic stem cells. Neuron 85:982997. CrossRef Medline

Miyoshi Y, Date I, Ohmoto T (1995a) Three-dimensional morphological study of microvascular regeneration in cavity wall of the rat cerebral cortex using scanning electron microscope: implications for delayed neural grafting into brain cavities. Exp Neurol 131:69-82. CrossRef Medline

Miyoshi Y, Date I, Ohmoto T (1995b) Neovascularization of rat fetal neocortical grafts transplanted into a previously prepared cavity in the cerebral cortex: a three-dimensional morphological study using the scanning electron microscope. Brain Res 681:131-140. CrossRef Medline

Montoya CP, Campbell-Hope LJ, Pemberton KD, Dunnett SB (1991) The 
"staircase test": a measure of independent forelimb reaching and grasping abilities in rats. J Neurosci Methods 36:219-228. CrossRef Medline

Nag S, Takahashi JL, Kilty DW (1997) Role of vascular endothelial growth factor in blood-brain barrier breakdown and angiogenesis in brain trauma. J Neuropathol Exp Neurol 56:912-921. CrossRef Medline

Nag S, Eskandarian MR, Davis J, Eubanks JH (2002) Differential expression of vascular endothelial growth factor-A (VEGF-A) and VEGF-B after brain injury. J Neuropathol Exp Neurol 61:778-788. CrossRef Medline

Neafsey EJ, Sørensen JC, Tønder N, Castro AJ (1989) Fetal cortical transplants into neonatal rats respond to thalamic peripheral stimulation in the adult. An electrophysiological study of single-unit activity. Brain Res 493: 33-40. CrossRef Medline

Nieto-Sampedro M, Whittemore SR, Needels DL, Larson J, Cotman CW (1984) The survival of brain transplants is enhanced by extracts from injured brain. Proc Natl Acad Sci U S A 81:6250-6254. CrossRef Medline

Okabe M, Ikawa M, Kominami K, Nakanishi T, Nishimune Y (1997) Green mice as a source of ubiquitous green cells. FEBS Lett 407:313-319. CrossRef Medline

Olson L, Seiger A, Stromberg I (1982) Intraocular transplantation in rodents: a detailed account of the procedure and example of its use in neurobiology with special reference to brain tissue grafting. In: Advances in cellular neurobiology, Vol 4 (Federoff S, Hertz L, eds), pp 407-442. New York: Academic.

Ourednik J, Ourednik V, Lynch WP, Schachner M, Snyder EY (2002) Neural stem cells display inherent mechanism for rescuing dysfunctional neurons. Nat Biotechnol 20:1103-1110. CrossRef Medline

Pinaudeau C, Gaillard A, Roger M (2000) Stage of specification of the spinal cord and tectal projections from cortical grafts. Eur J Neurosci 12:24862496. CrossRef Medline

Plumet J, Ebrahimi A, Guitet J, Roger M (1993) Partial recovery of skilled forelimb reaching after transplantation of fetal cortical tissue in adult rats with motor cortex lesion-anatomical and functional aspects. Restor Neurol Neurosci 6:9-27. Medline

Riolobos AS, Heredia M, de la Fuente JA, Criado JM, Yajeya J, Campos J, Santacana M (2001) Functional recovery of skilled forelimb use in rats obliged to use the impaired limb after grafting of the frontal cortex lesion with homotopic fetal cortex. Neurobiol Learn Mem 75:274-292. CrossRef Medline

Roome RB, Bartlett RF, Jeffers M, Xiong J, Corbett D, Vanderluit JL (2014) A reproducible Endothelin-1 model of forelimb motor cortex stroke in the mouse. J Neurosci Methods 233:34-44. CrossRef Medline

Rosenstein JM, Brightman MW (1978) Intact cerebral ventricle as a site for tissue transplantation. Nature 275:83-85. CrossRef Medline

Santos-Torres J, Heredia M, Riolobos AS, Jiménez-Díaz L, Gómez-Bautista V, de la Fuente A, Criado JM, Navarro-López J, Yajaya J (2009) Electrophysiological and synaptic characterization of transplanted neurons in adult rat motor cortex. J Neurotrauma 26:1593-1607. CrossRef Medline

Senatorov VV, Obuhova GP, Fülöp Z (1991) Electrophysiological and morphological properties of embryonic neocortical grafts developing in different regions of the host rat brain. J Neural Transplant Plast 2:125-140. CrossRef Medline

Sköld MK, von Gertten C, Sandberg-Nordqvist AC, Mathiesen T, Holmin S (2005) VEGF and VEGF receptor expression after experimental brain contusion in rat. J Neurotrauma 22:353-367. CrossRef Medline

Teng H, Zhang ZG, Wang L, Zhang RL, Zhang L, Morris D, Gregg SR, Wu Z, Jiang A, Lu M, Zlokovic BV, Chopp M (2008) Coupling of angiogenesis and neurogenesis in cultured endothelial cells and neural progenitor cells after stroke. J Cereb Blood Flow Metab 28:764-771. CrossRef Medline

Thompson LH, Grealish S, Kirik D, Björklund A (2009) Reconstruction of the nigrostriatal dopamine pathway in the adult mouse brain. Eur J Neurosci 30:625-638. CrossRef Medline

Tuszynski MH (2007) Rebuilding the brain: resurgence of fetal grafting. Nat Neurosci 10:1229-1230. CrossRef Medline

Ueno M, Yamashita T (2011) Kinematic analyses reveal impaired locomotion following injury of the motor cortex in mice. Exp Neurol 230:280290. CrossRef Medline

Whishaw IQ, Piecharka DM, Zeeb F, Stein DG (2004) Unilateral frontal lobe contusion and forelimb function: chronic quantitative and qualitative impairments in reflexive and skilled forelimb movements in rats. J Neurotrauma 21:1584-1600. CrossRef Medline

Wictorin K, Brundin P, Gustavii B, Lindvall O, Björklund A (1990) Reformation of long axon pathways in adult rat central nervous system by human forebrain neuroblasts. Nature 347:556-558. CrossRef Medline 